Characterization and Refinement of Carbide Coating Formation Rates and Dissolution Kinetics in the Ta-C System

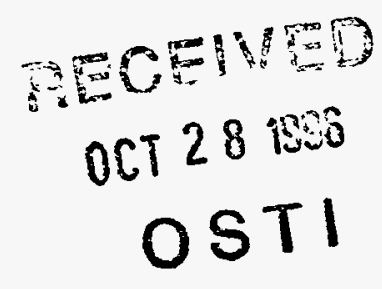

UNLMITED

HSTRIBUTION OF THIS DOCUMENT IS

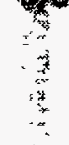


This thesis was accepted by the Department of Mechanical Engineering at the University of New Mexico, Albuquerque, New Mexico, in partial fulfillment of the requirements for the degree of Master of Science in Mechanical Engineering. The text and illustrations are the independent work of the author and only the front matter has been edited by the CIC-1 Writing and Editing staff to conform with Department of Energy and Los Alamos National Laboratory publication policies.

An Affirmative Action/Equal Opportunity Employer

This report was prepared as an account of work sponsored by an agency of the United States Government. Neither The Regents of the University of California, the United States Government nor any agency thereof, nor any of their employees, makes any warranty, express or implied, or assumes any legal liability or responsibility for the accuracy, completeness, or usefulness of any information, apparatus, product, or process disclosed, or represents that its use would not infringe privately owned rights. Reference herein to any specific commercial product, process, or service by trade name, trademark, manufacturer, or otherwise, does not necessarily constitute or imply its endorsement, recommendation, or favoring by The Regents of the University of California, the United States Government, or any agency thereof. The views and opinions of authors expressed herein do not necessarily state or reflect those of The Regents of the University of California, the United States Government, or any agency thereof. The Los Alamos National Laboratory strongly supports academic freedom and a researcher's right to publish; therefore, the Laboratory as an institution does not endorse the viewopoint of a publication or guarantee its technical correctness. 
Characterization and Refinement of Carbide Coating Formation Rates and Dissolution Kinetics in the Ta-C System

Patrick James Rodriguez

\section{Los Alamos \\ NATIONAL LABORATORY}

Los Alamos, New Mexico 87545 


\section{DISCLAIMER}

Portions of this document may be illegible in electronic image products. Images are produced from the best available original document. 



\section{Acknowledgments}

The author would like to thank the many people who were instrumental in the execution and completion of this work: special thanks go to committee members Dr. Keith Axler and thesis advisor Martin Weiser for their invaluable technical guidance, dedication, and mentoring. An appreciation is expressed to thesis committee members Dr. David Olivas and Dr. Arsalan Razani for their time and support. Special thanks go to Peter Lopez and Ramiro Pereyra for their technical support and assistance. An appreciation is expressed to Daniel Martinez, Joe Riedel, Charles Radosevich, Dennis Lujan and Mark Miller for their technical and moral support.

This work was conducted at Weapon Component Technology Group, Nuclear Material Technology Division of Los Alamos National Laboratory. A special thanks to the group management, Darrell Hays, Joseph Martz, Stephanie Hale, and Rueben Gutierrez for granting the opportunity and support necessary to conduct this research. The author extends appreciation to the GEM Fellowship for making the opportunity of graduate school available. 


\section{Table of Contents}

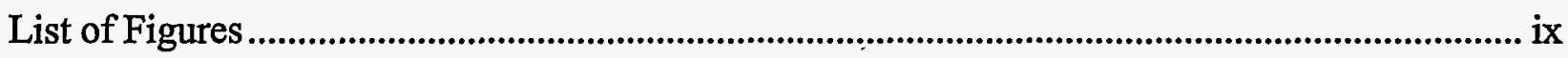

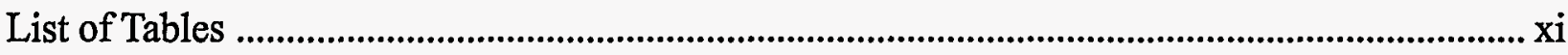

Nomenclature ........................................................................................................................ xii

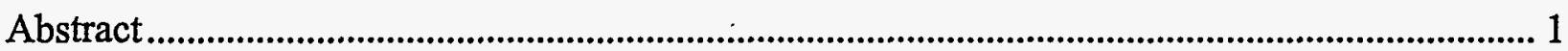

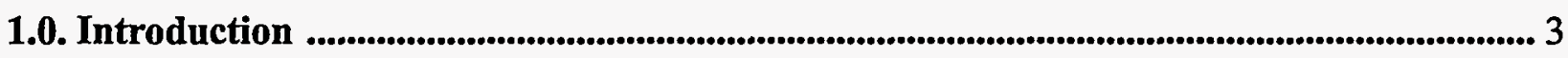

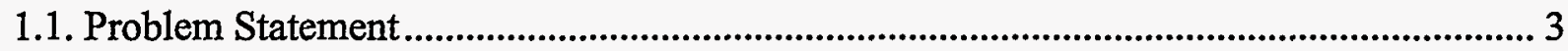

1.2. Introduction to Investigated Materials .............................................................................. 3

2.0. Background and Theory ................................................................................................................... 5

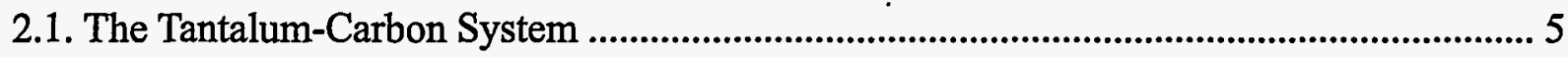

2.2. Formation of Tantalum Carbide Coatings .......................................................................... 7

2.2.1. Diffusion of Carbon in $\mathrm{TaC}$ and $\mathrm{Ta}_{2} \mathrm{C}$................................................................. 9

2.3. Diffusion of Carbon in Tantalum Metal ......................................................................... 10

2.3.1. Solubility Limit of Carbon in Tantalum ........................................................... 11

2.3.2. Interstitial Diffusion of Carbon ........................................................................ 14

2.4. Applications of Tantalum Carbides ................................................................................. 16

3.0. Experimental Procedure ................................................................................................................. 19

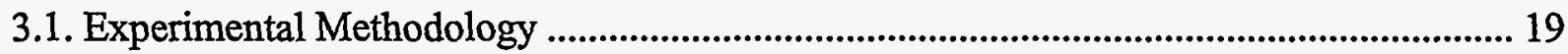

3.1.1. Carburization Time Selection ............................................................................... 19

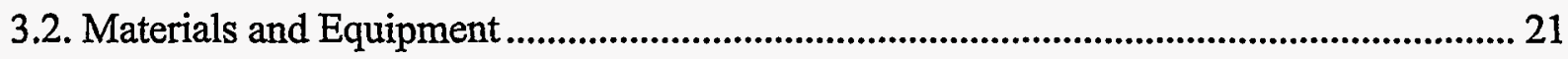

3.3. Preparation For Experimentation .............................................................................. 22

3.3.1. Packed-Bed Carburization ......................................................................................... 23

3.3.2. Preparation of Carbon-Saturated Specimens .............................................................. 26

3.3.2.1. Specimen Surface Preparation .......................................................................... 27

3.3.3. Preliminary Packed-Bed Carburization Studies ........................................................ 27

3.3.3.1. Microprobe Analysis of Tantalum Carbide Coatings ......................................... 28

3.4. Metallographic Preparation of Carbide Coated Specimens ................................................. 29

3.5. Carbide Coating Thickness Measurement ....................................................................... 30 
4.0. Results and Discussions ..................................................................................................................... 33

4.1. Chamber Atmosphere Study .......................................................................................... 33

4.2. Process Assessment .......................................................................................................... 37

4.3. Results of the Simultaneous Carburization of Bare and

Presaturated Tantalum Comparison Study .......................................................................... 41

4.3.1. Discussion of Results from the Simultaneous Carburization of

Bare and Presaturated Tantalum Comparison Study .............................................. 46

4.4. Discussion of the Applications Carbon-Saturated Tantalum .............................................. 50

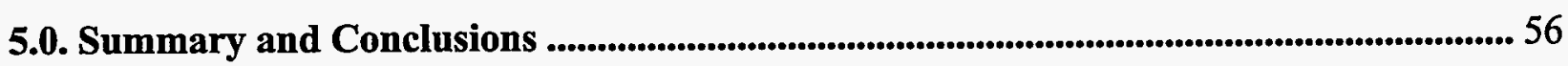

5.1. Further Accomplishments ......................................................................................... 56

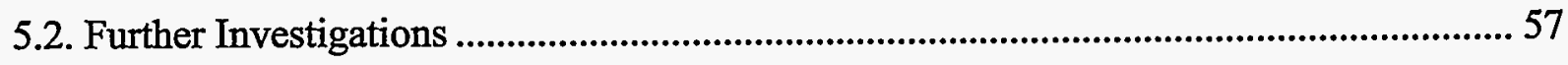

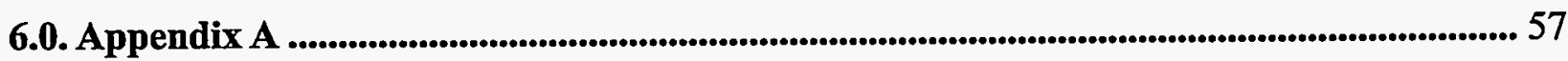

6.1. Digital Imaging Analysis For Carbide Layer Measurement.............................................. 57

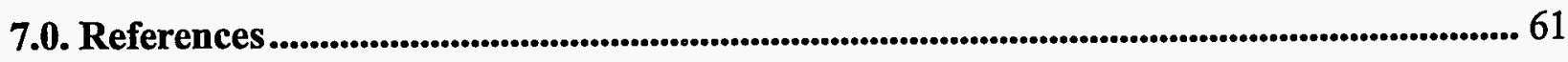




\section{List of Figures}

Figure 2.1. Tantalum-carbon binary phase diagram.

Figure 2.2. Reflective light photomicrographs of typical specimens prepared in this investigation. 8

Figure 2.3. Plot of diffusion rates of carbon in tantalum, $\mathrm{TaC}$, and $\mathrm{Ta}_{2} \mathrm{C}$ as a function of time.

Figure 2.4. Region of the tantalum-carbon binary phase diagram that illustrates the solubility limits of carbon in tantalum.

Figure 2.5. Dimensionless plot describing concentrations of diffusing species within a cylindrical geometry. 15

Figure 2.6. Reflective light photomicrographs of the effects of molten plutonium on tantalum metal. 18

Figure 3.1. Plot illustrating the carbide coating thickness deficiencies observed in a previous investigation.

Figure 3.2. Photograph of graphite containment crucible and lid. 25

Figure 3.3. Plot presenting the results of electron probe microanalysis Energy Dispersive Spectroscopy conducted on tantalum-carbide coatings.

Figure 3.4. Adobe Photoshop digital image of typical digital optical carbide coating thickness measurement scans.

Figure 4.1. Reflective light photomicrograph of tantalum in the as-received bare condition.

Figure 4.2. Reflective light photomicrograph of tantalum after carburization. 
Figure 4.3. Reflective light photomicrograph of tantalum after thermal processing.

Figure 4.4. Plot of Gibbs free energies of formation for several elemental interactions.

Figure 4.5. Flowchart illustrating process flow of processed specimens. 43

Figure 4.6. Reflective light photomicrographs of test crucible tantalum in the as-received bare condition.

Figure 4.7. Reflective light photomicrographs of test crucible tantalum after carburization.

Figure 4.8. Reflective light photomicrographs of test crucible tantalum after annealing.

Figure 4.9. Reflective light photomicrographs of test crucible tantalum after an acid wash. 


\section{List of Tables}

Table 2.1. Diffusion data for carbon in TaC. 10

Table 2.2. Diffusion data for carbon in $\mathrm{Ta}_{2} \mathrm{C}$. 10

Table 3.1. Elemental analysis conducted on tantalum metal stock. 23

Table 3.2. Carbide coating thickness recorded during the preliminary evaluations of packed-bed carburization. 28

Table 4.1. Observed and theoretical coating thicknesses for test specimens carburized in the process assessment study.

Table 4.2. Observed and theoretical weight gains for test specimens carburized in the process assessment study.

Table 4.3. Percent of theoretical data attained for coating thickness and weight gain during the process assessment study. 40

Table 4.4. The carbide coating thickness equivalent that could be formed from the mole numbers of carbon in solution.

Table 4.5. Observed and theoretical coating thicknesses for test specimens carburized in the bare versus presaturated study. 42

Table 4.6. Observed and theoretical weight gains for test specimens carburized in the bare versus presaturated study.

Table 4.7. Percent of theoretical thickness and weight gain data recorded for all specimens over the course of this investigation. 


\section{Nomenclature}

$\bar{a}$

$\bar{c}$

W

$\mathrm{W}_{\mathrm{TaC}}$

$\mathrm{W}_{\mathrm{Ta} 2 \mathrm{C}}$

$\mathrm{W}_{\text {Tot }}$

$\mathrm{K}$

$\mathrm{K}_{\mathrm{TaC}}$

$K_{\text {a-Ta2C }}$

$\mathrm{K}_{\mathrm{b}-\mathrm{Ta2C}}$

$\mathrm{t}$

$\mathrm{t}_{\mathrm{s}}$

$\mathrm{T}$

R

D

D。

$\mathrm{Q}_{\text {act }}$

r

a

C

$\mathrm{C}_{\mathrm{o}}$

\section{$C_{1}$}

J

$\mathrm{J}_{1}$

$\alpha$

A

$\mathrm{H}$
Crystal lattice dimension

Crystal lattice dimension

Carbide coating layer thickness

TaC coating layer thickness

$\mathrm{Ta}_{2} \mathrm{C}$ coating layer thickness

Total carbide coating thickness

Carbide coating layer growth rate

Carbide coating layer growth rate for $\mathrm{TaC}$

Carbide coating layer growth rate for $\mathrm{a}-\mathrm{Ta}_{2} \mathrm{C}$

Carbide coating layer growth rate for $\mathrm{b}-\mathrm{Ta}_{2} \mathrm{C}$

Time

Time for saturation

Temperature

Universal gas constant

Diffusivity

Diffusion constant

Activation energy

radial position

Radius of cylinder

Carbon concentration at a specific radial position

Solid solubility limit of carbon in tantalum

Initial carbon concentration in tantalum

Bessel function of order zero

Bessel function of first order

Eigenvalue

Area of carbide within area analyzed

Height of area analyzed 


\title{
CHARACTERIZATION AND REFINEMENT OF CARBIDE COATING FORMATION RATES AND DISSOLUTION KNNETICS IN THE TA-C SYSTEM
}

by

\author{
Patrick James Rodriguez
}

\begin{abstract}
The interaction between carbide coating formation rates and dissolution kinetics in the tantalum-carbon system was investigated. The research was driven by the need to characterize carbide coating formation rates. The characterization of the carbide coating formation rates was required to engineer an optimum processing scheme for the fabrication of the ultracorrosion-resistant composite, carbon-saturated tantalum. A packed-bed caburization process was successfully engineered and employed. The packed-bed carburization process produced consistent, predictable, and repeatable carbide coatings. A digital imaging analysis measurement process for accurate and consistent measurement of carbide coating thicknesses was developed. A process for removing the chemically stable and extremely hard tantalum-carbide coatings was also developed in this work.
\end{abstract}




\subsection{Introduction}

\subsection{Problem Statement}

In this thesis, the interaction between carbide coating formation rates and dissolution kinetics in the tantalum-carbon system is described. It has been observed that actual carbide coating layer thicknesses are generally less than that which would be calculated. At the inception of this investigation, the author proposed that as the $\mathrm{TaC} / \mathrm{Ta}_{2} \mathrm{C}$ carbide coating is forming, the coating is being depleted via decomposition of the carbide compounds and subsequent interstitial diffusion of nascent carbon into the tantalum substrate as the system moves towards equilibrium.

The objective of this work was to investigate and better characterize the interactions of carbide coating and carbon dissolution phenomena in the tantalum-carbon system. The directive was to determine if the digestion of surface carbide coatings by dissolving carbon into the metal substrate is responsible for the disparity between theoretical and actual coating growth. The research was driven by the need to characterize carbide coating formation rates. The characterization of the carbide coating formation rates was required in order to engineer an optimum processing scheme for the fabrication of carbon-saturated tantalum ${ }^{1}$ hardware.

\subsection{Introduction to Investigated Materials}

The transition metal tantalum is one of the most corrosion-resistant metals. In most environments, tantalum is almost as inert as gold or platinum. However, the price of tantalum is about 10 percent of that of the noble metals. ${ }^{1}$

Tantalum can be cold worked and machined. Fully recrystallized tantalum has an ultimate strength ${ }^{1}$ of 689-1034 $\mathrm{MPa}$. In general, tantalum presents a non-wetting surface to most liquids. Tantalum parts used in corrosive environments generally exhibit extended longevity because thermal cycling does not affect its surface finish and corrosion by many conventional liquid metals and salts is minimal.

Tantalum's corrosion-resistance can be attributed to the presence of a thin surface oxide $\left(\mathrm{Ta}_{2} \mathrm{O}_{5}\right)$. Tantalum as a metal is thirty-fourth on the Pourbaix thermodynamic nobility table. But the oxide, $\mathrm{Ta}_{2} \mathrm{O}_{5}$, is second on the Pourbaix thermodynamic nobility table. ${ }^{2}$

The majority of tantalum used in the United States of America is by industries employing corrosive chemicals. About one half the tantalum used in the chemical industry is employed by 
processes involving sulfuric acid. Tantalum heating surfaces are used in plants for the reconcentration of sulfuric acid arising from metal pickling, oil refinery operations, and petrochemical processing to produce alcohol and ketones. Tantalum is extensively used in the production and handling of hydrochloric acid, hydrobromic acid, and many of their derivatives. Operations involving chlorine or chloride derivatives employ about one-fourth the tantalum used in the chemical industry. Tantalum is one of the few metals resistant to aqua regia (nitrohydrochloric acid). Plants employing aqua regia to refine precious metals use tantalum extensively. Tantalum is widely used in the production of high purity nitric acids, ammonium nitric, and terephthalic acid. Industries such as the pharmaceutical and food industries which cannot tolerate the smallest amount of impurity contamination use tantalum because of its negligible corrosion rate.

Nuclear material pyrochemical and pyrometallurgical processes employ tantalum in the construction of various processing components. Although tantalum is one of the more corrosionresistant metals, it is not entirely inert in some of the extremely corrosive environments employed in the processing of some nuclear materials. Interactions between processing materials and processing components generally create quality control issues. Failed hardware can be cause for interrupted or failed runs. Interrupted or halted runs can lead to added exposure to radioactivity for material processing personnel. Degraded or failed components must be discarded as radioactive waste.

In an effort to reduce radioactive waste, personnel exposure to radioactivity, and to improve process quality at Los Alamos National Laboratory, an effort was undertaken to engineer a mechanically robust, corrosion-resistant processing component construction material. The effort led to the development of a carbon-saturated tantalum composite. ${ }^{3}$ The preparation of the composite involves first laying down a tantalum-carbide coating on the surface of bare (carbonfree/uncarburized) tantalum via carburization. Then, subsequent thermal processing is performed to invoke an optimum microstructure of $\mathrm{Ta}_{2} \mathrm{C}$ precipitates.

In the study by Axler ${ }^{3}$ describing the development of the carbon-saturated composite, carburization was performed by gas phase carburization. The carbide coating thicknesses achieved ranged from 24 to 62 percent of theoretical thickness. This large deviation and the deficiencies in observed coating thicknesses make it difficult to calculate predictable carburization parameters to suit an efficient processing scheme. Thus, it was intended that the proceeds of characterizing and understanding the interaction between carbide formation rates and dissolution kinetics would enable the development of an optimum processing scheme for fabricating carbonsaturated hardware. 


\subsection{Background and Theory}

An extensive review of the available literature was completed before the present investigation was conducted. The nature of select tantalum-based material applications is sensitive to national security. Therefore, the review at hand includes a search of the open literature, internal documents within the United States National Laboratories, Los Alamos National Laboratory archives, and private communications with relevant investigators.

\subsection{The Tantalum-Carbon System}

The first reported works on the tantalum-carbon system focused on the 1:1 intermediate phase, tantalum monocarbide. Van Arke first reported the crystal structure of TaC in 1924. The monocarbide $\mathrm{TaC}$ is cubic, an $\mathrm{NaCl}$ prototype, with $=4.45 \mathrm{è}$. This crystal structure has been confirmed by other investigators. ${ }^{5-12}$

A second tantalum-carbon compound, $\mathrm{Ta}_{2} \mathrm{C}$, was first reported in 1934 by Burgers and Basart. ${ }^{13}$ They reported that $\mathrm{Ta}_{2} \mathrm{C}$ has a hexagonal structure with $\mathrm{a}=3.097 \mathrm{è} \mathrm{and}=4.94 \mathrm{è}$. Ellinger ${ }^{14}$ in 1943 confirmed the hexagonal structure.

Ellinger ${ }^{14}$ published the first extensive work on the tantalum-carbon system phase behavior in 1943. In that work a tentative phase diagram was presented. The majority of the phase boundaries in that work were estimated. A reproduction of Ellinger's phase diagram presentation still appears in the compilations of Hansen ${ }^{15}$ and Shunk. ${ }^{16}$ Kieffer and Benesovsky ${ }^{17}$ in 1963 published a work containing the presentation of the phase diagram. This construction was an expansion on Ellinger's work with the inclusion of further experimental data.

Rudy and Harmon ${ }^{18}$ published the most recent contribution of data to the tantalum-carbon phase diagram. Their diagram includes data produced by an adjunctive approach incorporating $x$-ray diffraction, chemical analysis, and differential thermal analysis (DTA). The authors noted that they used the analogous niobium-carbon system ${ }^{19}$ as a template for their investigations. Moffa $t^{20}$ reproduces Rudy and Harmon's presentation of the phase diagram in his compilation but makes reference to a later publication by Rudy and Harmon. ${ }^{21}$ This later publication is a compilation representing their original work.

A construction of the tantalum-carbon binary system phase diagram reflecting interpretations by the current author appears in Figure 2.1. The construction of the binary phase diagram is based on interpretations of the published data. 


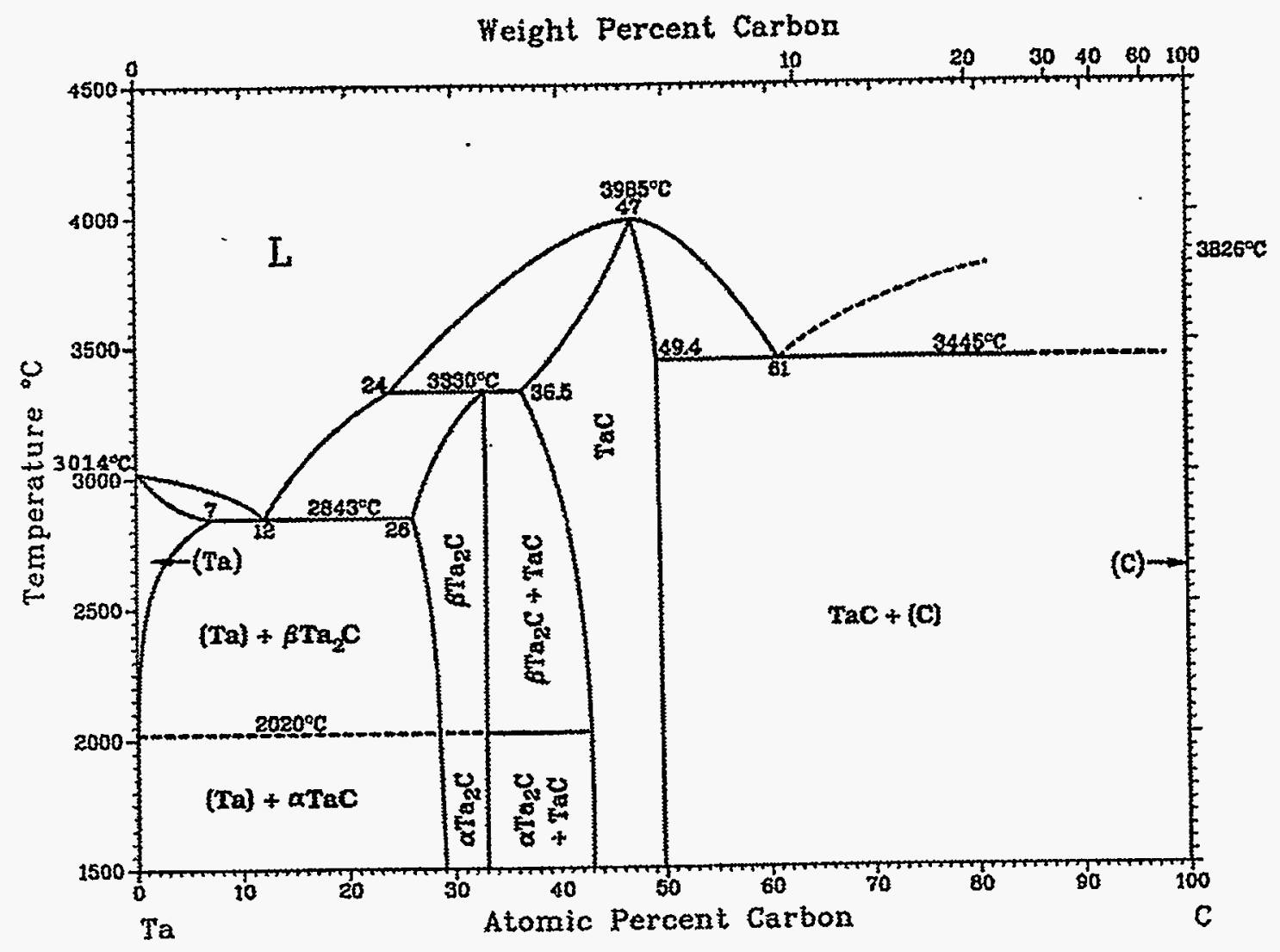

Figure 2.1. Tantalum-carbon binary phase diagram.

The $\mathrm{b}-\mathrm{Ta}_{2} \mathrm{C}$ compound is formed in a peritectic reaction at approximately 36.5 at.\% carbon at $3330^{\circ} \mathrm{C}$. The $\mathrm{b}-\mathrm{Ta}_{2} \mathrm{C}$ phase undergoes a polymorphic transformation to the $\mathrm{a}-\mathrm{Ta}_{2} \mathrm{C}$ phase at a range of homogeneity of approximately 28.5 to 33 at.\% carbon between the temperatures of 2100 to $2020^{\circ} \mathrm{C}$. At temperatures below $1400^{\circ} \mathrm{C}$ and compositions between 0 and 29 at.\% carbon, carbon is not soluble in tantalum. Thus, a two phase region of tantalum metal and a- $\mathrm{Ta}_{2} \mathrm{C}$ precipitate exits. Between the temperatures of 3014 and $1400^{\circ} \mathrm{C}$ tantalum exhibits a small solubility for carbon. The maximum solubility is 7 at. $\%$ at just below $2843^{\circ} \mathrm{C}$.

The phase diagram is less complex on the carbon-rich end. $\mathrm{TaC}$ melts congruently at a composition of 47 at. $\%$ carbon at approximately $3985^{\circ} \mathrm{C}$. The largest range of homogeneity of the $\mathrm{TaC}$ phase occurs at $3330^{\circ} \mathrm{C}$ with a composition ranging from 36.3 to $\sim 49.7$ at. $\%$ carbon. The homogenous range of the phase extends from 42.5 to 49.8 at.\% carbon at $1700^{\circ} \mathrm{C}$. The phase forms a eutectic with carbon at 61 at. $\%$ carbon at $3445^{\circ} \mathrm{C}$. In all published phase diagrams, $\mathrm{TaC}$ exists in equilibrium with carbon from 49.8 to 100 at.\%. Apparently the solid solution of tantalum in carbon is non-existent. However, there has been very little work done on the carbon-rich region of the phase diagram. 
$\mathrm{TaC}$ is one of the highest melting point materials known. Numerous investigations ${ }^{21-28}$ have reported values for the melting point of $\mathrm{TaC}$, but there is a considerable degree of inconsistency between these reported melting points. The melting point of $\mathrm{TaC}$ has been reported since the characterization of this material first began in 1925. Reported values for the melting point range from 3540 to $4200^{\circ} \mathrm{C}$, as reported by Geach et al. ${ }^{26}$ and Bowman, ${ }^{22}$ respectively. The most recent work reporting the characterization of the melting point was reported by Rudy and Harmon $^{21}$ (1965). In their work they reported a melting point value of $3983^{\circ} \mathrm{C}$. The inconsistencies in the reported melting point can be attributed to two principal factors: the difficulty associated with accurately measuring temperature at such high temperatures and the difficulty of obtaining well characterized single-phase specimens.

\subsection{Formation of Tantalum Carbide Coatings}

Formation of carbides on the surface of tantalum has principally been investigated by five investigators. ${ }^{3-32}$ The work of Krikorian et al. ${ }^{29}$ work is the only literature specifically dedicated to the growth of carbide layers on the surface of tantalum. The other literature ${ }^{30,31,32}$ reports carbide thickness in studies of carbon diffusion in the tantalum carbides.

Upon carburization of tantalum both intermediates of tantalum carbide, $\mathrm{TaC}$ and $\mathrm{Ta}_{2} \mathrm{C}$, are observed to form concurrently on the surface of the originally bare tantalum. The more carbon rich intermediate, $\mathrm{TaC}$, forms at the surface closest to the carbon source. The more metal rich intermediate, $\mathrm{Ta}_{2} \mathrm{C}$, forms between $\mathrm{TaC}$ and the metal substrate. Two reflective light photomicrographs of typical specimens prepared in the current investigation are presented in Figure 2.2. The monocarbide intermediate is the uppermost carbide layer observed in each photomicrograph. The $\mathrm{Ta}_{2} \mathrm{C}$ intermediate is the carbide layer observed below the $\mathrm{TaC}$. And, $\mathrm{Ta}_{2} \mathrm{C}$ precipitate decorated tantalum metal is the material observed in the lower regions of the photomicrographs. 

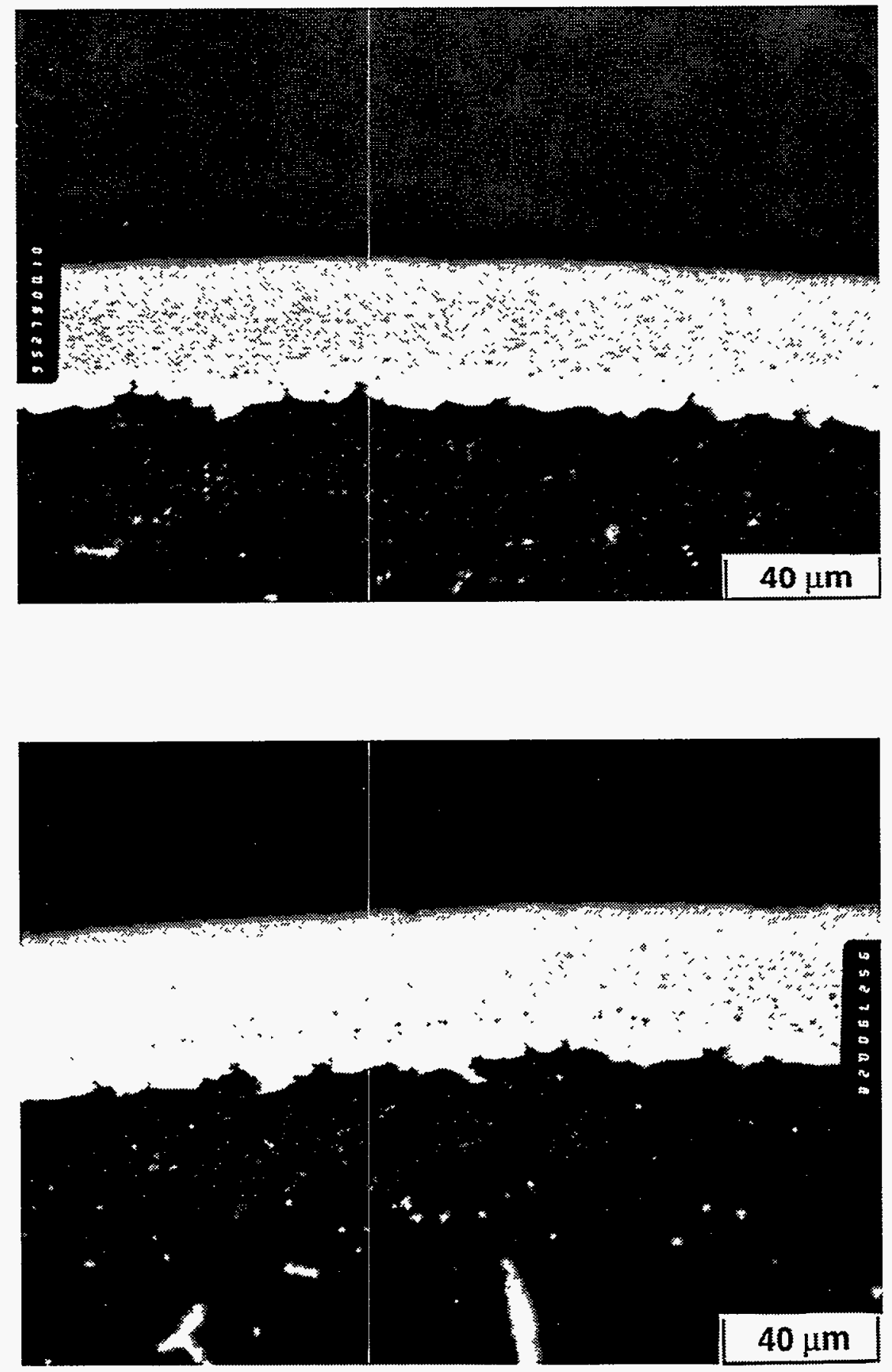

Figure 2.2. Reflective light photomicrographs of typical specimens prepared in the current investigation are presented above. The monocarbide intermediate is the uppermost carbide layer observed in each photomicrograph. The $\mathrm{Ta}_{2} \mathrm{C}$ intermediate is the carbide layer observed below the $\mathrm{TaC} . \mathrm{And}, \mathrm{Ta}_{2} \mathrm{C}$ precipitate decorated tantalum metal is the material observed in the lower regions of the photomicrographs. 
The works on carbide coating formation previously cited ${ }^{29-32}$ are based on measurement of the layer growth. The thickness of the measured phases displayed parabolic growth rate with time. When carbide thicknesses are plotted logarithmically as a function of time, the points may be represented linearly with a slope of one-half. Therefore, the growth of the carbide layers is described by the expression

$$
\mathrm{W}=[\mathrm{Kt}]^{1 / 2},
$$

where $\mathrm{W}$ is the thickness of the phase, $\mathrm{K}$ is a temperature-dependent rate constant $\left(\mathrm{cm}^{2} / \mathrm{s}\right)$, and $\mathrm{t}$ is time (seconds). The total carbide thickness can be calculated by summing the thickness of each phase:

$$
\mathrm{W}=\mathrm{W}_{\mathrm{TaC}}+\mathrm{W}_{\mathrm{Ta} 2 \mathrm{C}}
$$

Krikorian et al. ${ }^{29}$ in their work presented a composite plot of all the pertinent data relating to the rate constants, $\mathrm{K}$. In this plot the average rate constants for the diffusion of carbon in the three phases of tantalum carbide are given on the basis of a least squares treatment of the data. That plot represented data taken from the work of Brizes, ${ }^{30}$ Resnick et al., ${ }^{31}$ Fromm et al., ${ }^{32}$ and contributions of their own work. The rate constants reported by Krikorian et al. are used in the current study for calculating theoretical carbide coating growth.

$$
\begin{array}{ll}
\mathrm{K}_{\mathrm{TaC}}=1.27 \mathrm{X} 10^{-2}\left(\mathrm{~cm}^{2} / \mathrm{sec}\right) \exp [-71,200(\mathrm{cal} / \mathrm{mole}) / \mathrm{RT}] & {\left[1200<\mathrm{T}<2800^{\circ} \mathrm{C}\right]} \\
\mathrm{K}_{\mathrm{a}-\mathrm{Ta} 2 \mathrm{C}}=1.94 \mathrm{X} 10^{-2}\left(\mathrm{~cm}^{2} / \mathrm{sec}\right) \exp [-77,600(\mathrm{cal} / \mathrm{mole}) / \mathrm{RT}] & {\left[1200<\mathrm{T}<2020^{\circ} \mathrm{C}\right]} \\
\mathrm{K}_{\mathrm{b}-\mathrm{Ta} 2 \mathrm{C}}=11.8\left(\mathrm{~cm}^{2} / \mathrm{sec}\right) \exp [-100,000(\mathrm{cal} / \mathrm{mole}) / \mathrm{RT}] & {\left[2020<\mathrm{T}<2800^{\circ} \mathrm{C}\right]}
\end{array}
$$

Brizes has shown that the growth of the carbide layers is due to diffusion of carbon and not tantalum. Given this fact along with knowledge of the composition at the $\mathrm{TaC} / \mathrm{Ta}_{2} \mathrm{C}$ phase boundary, it is possible to use the Kirkendall effect theory to calculate diffusion coefficients of carbon in each phase. The Kirkendall effect theory is covered in a text by Weiser. ${ }^{33}$

\subsubsection{Diffusion of Carbon in $\mathrm{TaC}$ and $\mathrm{Ta}_{2} \mathrm{C}$}

The diffusion of carbon in $\mathrm{TaC}$ and $\mathrm{Ta}_{2} \mathrm{C}$ was investigated by Brize, ${ }^{30}$ Resnick et al., ${ }^{31}$ Fromm et al., ${ }^{32}$ Resnick and Seigle, ${ }^{34}$ and Tobin et al. ${ }^{35}$ Resnick et al. demonstrated that diffusivity of carbon in TaC varies with composition. Diffusivity of carbon decreases with increasing carbon concentration. However, the variability is so small that the diffusivity is 
virtually independent of composition. The diffusivity variability of carbon in $\mathrm{Ta}_{2} \mathrm{C}$ is of less significance due to the small compositional range of $\mathrm{Ta}_{2} \mathrm{C}$. For the applications of interest in this investigation, average diffusion coefficients over the composition range of $\mathrm{TaC}_{\mathrm{C}}$ and $\mathrm{Ta}_{2} \mathrm{C}$ are sufficient. Average diffusion coefficients reported in the literature are presented in .Table 2.1 and Table 2.2.

Table 2.1. Diffusion data for carbon in TaC.

\begin{tabular}{||c|c|l||}
\hline $\begin{array}{c}\mathrm{D}_{\mathrm{o}} \\
{\left[\mathrm{cm}^{2} \text { /sec. }\right]}\end{array}$ & \multicolumn{1}{|c|}{$\begin{array}{c}\mathrm{Q}_{\text {act }} \\
{[\mathrm{cal} / \mathrm{mol}]}\end{array}$} & \multicolumn{1}{|c|}{ References } \\
\hline \hline 2.00 & 90,700 & Brize $^{30}$ \\
\hline 1.40 & 86,000 & Resnick et al. $^{31}$ \\
\hline 8.8 & 98,800 & Fromm et al. $^{32}$ \\
\hline 0.18 & 85,000 & Resnick and Seigle $^{34}$ \\
\hline 1.8 & 87,000 & Tobin et al. $^{35}$ \\
\hline
\end{tabular}

Table 2.2. Diffusion data for carbon in $\mathrm{Ta}_{2} \mathrm{C}$.

\begin{tabular}{||c|c|l|}
\hline $\begin{array}{c}\mathrm{D}_{\circ} \\
{\left[\mathrm{cm}^{2} / \mathrm{sec} .\right]}\end{array}$ & $\begin{array}{c}\mathrm{Q}_{\text {act }} \\
{[\mathrm{cal} / \mathrm{mol}]}\end{array}$ & \multicolumn{1}{|c|}{ References } \\
\hline $1 \times 10^{3}$ & $89,0 \overline{0}$ & Brize $^{30}$ \\
\hline 7.0 & 89,000 & Resnick et al. $^{34}$ \\
\hline 2.70 & 85,000 & Fromm et al. $^{32}$ \\
\hline
\end{tabular}

\subsection{Diffusion of Carbon in Tantalum Metal}

The diffusion of carbon in tantalum metal has been investigated by Powers and Doyle..$^{36}$ In their work they measured interstitial carbon diffusion rates indirectly using a mechanical relaxation technique ${ }^{37}$ originally developed to measure interstitial diffusion rates of solute atoms in a-iron. The technique relates a stress/strain relaxation time to the diffusion coefficient, $\mathrm{D}$, for the interstitial solute in the metal. Powers and Doyle measure the relaxation times by two separate methods: measurement of internal friction peaks and the measurement of elastic after-effect. The parameters $D_{0}$ and $Q_{a c t}$ of the Arrhenius expression, $D=D_{0} \exp \left[-Q_{a c t} /(R T)\right]$, were obtained by means of least squares fitting plotted data of the natural log of relaxation time versus reciprocal 
temperature. The result yielded by performing the analysis for relaxation times via the two independent methods of measurement produced values of $\mathrm{D}_{\mathrm{o}}$ and $\mathrm{Q}_{2 \mathrm{ct}}$ that were in good agreement. The authors used a combined weighted value of both relaxation time measurements to arrive at values of $D_{0}=0.0061 \mathrm{~cm}^{2} / \mathrm{sec}$ and $Q_{a c t}=38,510 \mathrm{cal} / \mathrm{mole}$. The values for $D_{0}$ and $Q_{\text {act }}$ reported by Powers and Doyle were used in all interstitial diffusion of carbon in tantalum calculations performed in the current work.

In general, the diffusion rate of carbon in tantalum metal is faster than that in $\mathrm{TaC}$ and $\mathrm{Ta}_{2} \mathrm{C}$. The diffusion rate coefficients for diffusion of carbon in tantalum metal, $\mathrm{TaC}$, and $\mathrm{Ta}_{2} \mathrm{C}$ have been plotted as a function of temperature in Figure 2.3. Diffusion coefficient values for $\mathrm{TaC}_{\text {and }} \mathrm{Ta}_{2} \mathrm{C}$ were calculated based on diffusion rate data reported by Brizes. ${ }^{30}$ At $1700^{\circ} \mathrm{C}$ (the temperature of interest in the current investigation), diffusion of carbon in tantalum is three orders of magnitude faster than that of diffusion in $\mathrm{TaC}$ and $\mathrm{Ta}_{2} \mathrm{C}$.

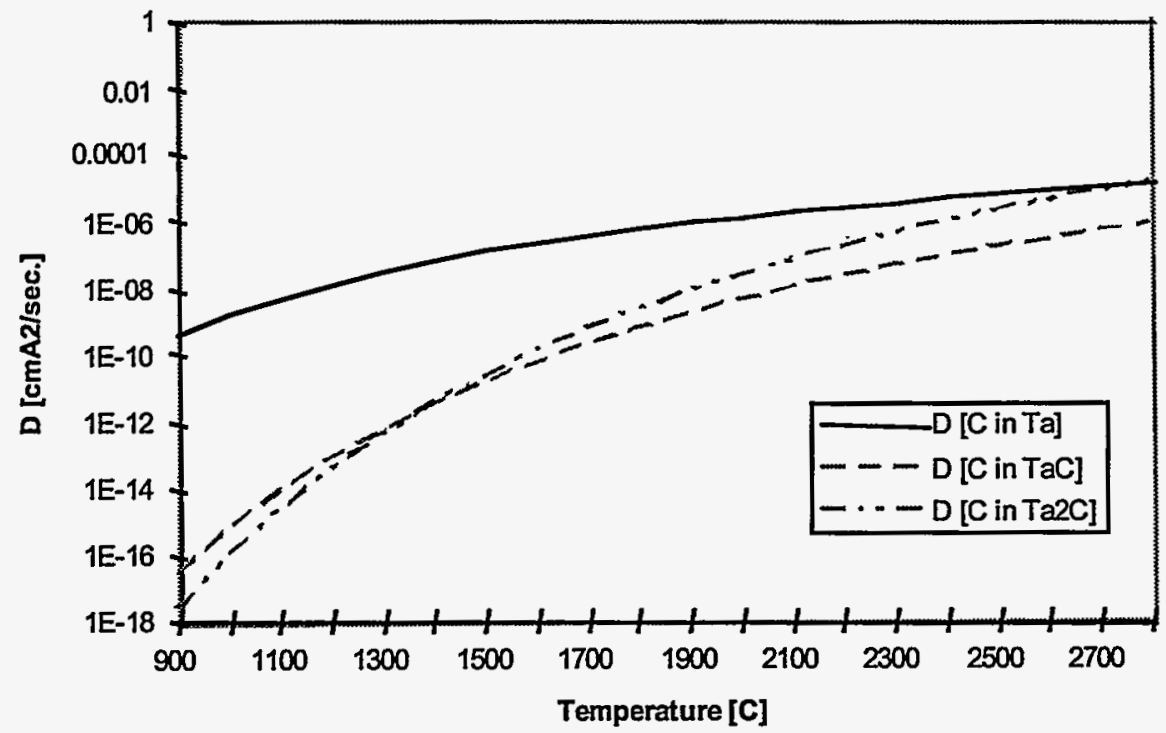

Figure 2.3. The diffusion rate coefficients for diffusion of carbon in tantalum metal, $\mathrm{TaC}$, and $\mathrm{Ta}_{2} \mathrm{Chave} \mathrm{been}$ plotted as a function of temperature. Diffusion coefficient values for diffusion of carbon in tantalum were calculated based on diffusion rate data reported by Powers and Doyle. ${ }^{36}$ Diffusion coefficient values for $\mathrm{TaC}^{\mathrm{C}}$ and $\mathrm{Ta}_{2} \mathrm{C}$ were calculated based on diffusion rate data reported by Brizes. ${ }^{30}$

\subsubsection{Solubility Limit of Carbon In Tantalum}

There have been several investigations $\mathrm{s}^{3,14,18,38-44}$ reporting the solubility limit of carbon in tantalum. The region of the tantalum-carbon binary phase diagram, which illustrates the solubility limits of carbon in tantalum, is presented in Figure 2.4. In this portion of the phase diagram the solvus line has been constructed using reported data of several independent researchers. 


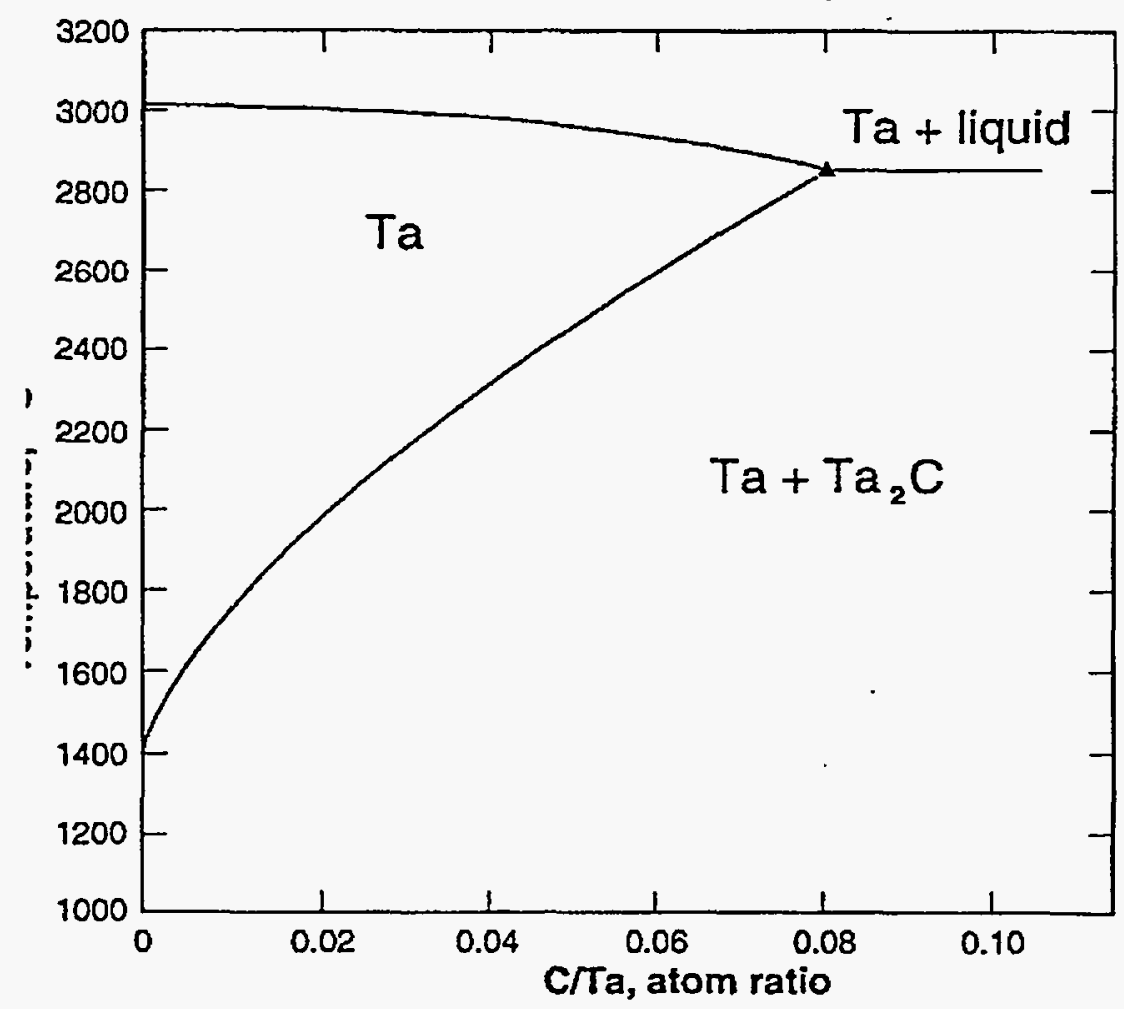

Figure 2.4. Region of the tantalum-carbon binary phase diagram that illustrates the solubility limits of carbon in tantalum. In this portion of the phase diagram, the solvus line has been constructed using reported data of several independent researchers.

In early investigations ${ }^{14,39,40}$ on the tantalum-carbon system, a generally lower terminal solubility of carbon was assumed. A solubility of approximately 0.3 at.\% carbon in tantalum at the eutectic temperature was generally accepted. In later investigations, Smirnove et al., ${ }^{38}$ Storms, ${ }^{42}$ Rudy and Harmon, ${ }^{18}$ and Fromm and Roy ${ }^{43}$ reported generally higher solubilities with a terminal solubility of approximately 3.0 at.\% carbon in tantalum at the eutectic temperature.

Fromm and Roy ${ }^{43}$ contributed a significant portion of data available on the terminal solubility of carbon in tantalum. In their investigation they carburized tantalum rods by induction heating the rods in close proximity to graphite cylindrical sleeves or crucible walls. The tantalum rods were prepared by pressing high-purity tantalum powder into pellets and electron beam arc-melting compacts. The compacts were then cold swagged into rods. The tantalum rods were carburized and then annealed for a time estimated to be sufficient to fully saturate the tantalum volume. The excess surface carbide layer was mechanically removed, and chemical analysis was performed. At temperatures between 1500 and $2200^{\circ} \mathrm{C}$, Fromm and Roy's results are in close agreement with those of Ogden et al. ${ }^{41}$ Chemical analysis generally involves complete digestion of a volume of material in an acid solution and then examination by spectroscopy methods. 
In their solubility study, Ogden et al. alloyed tantalum by additions of carbon during electron beam arc-melting of pure tantalum. These varying compositions were then annealed to allow precipitate formation at different temperatures. Metallographic examinations were used to determine the solvus temperature corresponding to a specific alloying content of carbon.

The most recent work on the solid solubility of carbon in tantalum is an investigation by $\operatorname{Axler}^{3}$ (1995) in which the kinetics of precipitate formation was investigated. Axler produced carbon saturated specimens by means of methane/argon gas phase caburization and subsequent annealing for carbon saturation. In that study, the solubility limit at one temperature was determined by chemical analysis and optical image analysis. Optical image analysis involved capturing optical metallography digitally on a computer then using an image analysis software package to measure the area fractions of the phases present. In Axler's study the use of both solubility measurements methods yielded nearly identical results, 0.997 at.\% carbon solubility limit at $1800^{\circ} \mathrm{C}$. The result of the solubility limit at this temperature was consistent with those of Ogden et al. and Fromm and Roy.

In contrast to previously discussed investigations, Hortz et al..$^{44}$ used a method to determine solubility directly during carburization/saturation at the processing temperature. Tantalum $0.5 \mathrm{~mm}$ diameter wire specimens were carburized/saturated in flowing acetylene. The dissolution of carbon was indirectly measured by continuously surveying the electrical resistivity of the metal at the carburization/saturation temperature.

In that work, Hortz et al. provided temperature expressions for the solubility limit instead of solvus line data. Two expressions were presented over two temperature regimes. The two expressions are discontinuous at the inflection temperature between the two temperature regimes. Hortz et al. make an assumption that the discontinuity in the solubility function is due to polymorphic transformation of $\mathrm{Ta}_{2} \mathrm{C}$ at this inflection temperature. However, the temperature where the discontinuity occurs is a minimum of $80^{\circ} \mathrm{C}$ lower than the polymorphic transformation temperature. In addition, no other work reports a pronounced change in solubility associated with this polymorphic transformation.

Using the expression provided by Hortz et al., the solubility limit at $1800^{\circ} \mathrm{C}$ would calculate to be 0.270 at.\% carbon in tantalum. This value is considerably higher than that reported by Axler ( 0.997 at.\% carbon in tantalum). 


\subsubsection{Interstitial Diffusion of Carbon}

The model for solid-state interstitial diffusion can be used to calculate diffusion rates of carbon in tantalum. The model for diffusion in an effectively infinitely long cylinder was used to calculate saturation rates of tantalum test specimens employed in the current investigation. The mathematical theory of diffusion is extensively covered in a text by Crank. ${ }^{45}$

During the course of this investigation, tantalum rods were used as test specimens in the carburization studies conducted. The rod test specimens employed did not provide an infinite volume for diffusion. Thus, the rate of diffusion of carbon in the tantalum rods was dependent on the concentration of carbon in the substrate. The rods were cut to lengths that were a minimum of eight times greater than the diameter. Thus, the theory for non-steady state diffusion in an effectively long cylinder was applied to calculate saturation rates.

The rate of carbon diffusion depends on the concentration of carbon in the tantalum substrate. The diffusion rate of carbon decreases as the concentration of carbon in the substrate increases. As the system works towards equilibrium, a carbon concentration gradient evolves over the radial distance. In his text, Crank presents a dimensionless plot that describes concentration distributions over the radial geometry of a cylinder in a non-steady state diffusion system. This plot is presented in Figure 2.5.

The values appearing on the ordinate axis of the plot, $\left[\mathrm{C}-\mathrm{C}_{1}\right] /\left[\mathrm{C}_{0}-\mathrm{C}_{1}\right]$, are the concentration fraction of the solubility limit. The values presented on the abscissa are normalized radial position, $r / a$, where $r$ is the radial position of interest and $a$ is the radius of the solid cylinder. (At the tantalum/tantalum carbide coating interface, $r / a$ is equal to one.)

The concentration fraction of the solubility limit, $\left[\mathrm{C}-\mathrm{C}_{1}\right] /\left[\mathrm{C}_{0}-\mathrm{C}_{1}\right]$, can be found by solving the diffusion equation for non-steady state radial diffusion in a solid cylinder of initial uniform concentration. Thus,

$$
\frac{\left[C-C_{1}\right]}{\left[C_{0}-C_{1}\right]}=1-\frac{2}{a} \sum_{n=1}^{\infty} \frac{\exp \left(-D t \alpha_{n}^{2}\right) J_{o}\left(r \alpha_{n}\right)}{\alpha_{n} J_{1}\left(a \alpha_{n}\right)}
$$

where $C$ is the carbon concentration at a specific radial position, $C_{1}$ is the initial carbon concentration in the tantalum, $\mathrm{C}_{\mathrm{o}}$ is the solid solubility of carbon in tantalum at the saturation temperature, $\mathrm{D}$ is the diffusion rate at the processing temperature, $t$ is time, $\mathrm{J}_{0}$ and $\mathrm{J}_{1}$ are Bessel functions 
of the order zero and first order, respectively, and $a_{n}$ are roots of the eigenfunction $J_{0}\left(a a_{n}\right)=0$, where $a$ is radius of the rod and $r$ is radial position.

The solution for the cylinder can be written in terms of the two dimensionless parameters, $\mathrm{Dt} / \mathrm{a}^{2}$ and $\mathrm{r} / \mathrm{a}$. The curves presented in Figure 2.5 are the curves for $\mathrm{Dt} / \mathrm{a}^{2}$ at $\mathrm{r} / \mathrm{a}$. The values on the curves are values of $\mathrm{Dt} / \mathrm{a}^{2}$. The curve for $\mathrm{Dt} / \mathrm{a}^{2}$ is linear and virtually horizontal at $\mathrm{Dt} /$ $\mathrm{a}^{2}=0.90$. This trend of the curve indicates that the substrate has reached a virtual uniform carbon concentration over its radial distance and the system has come to equilibrium. Thus, during the course of this work, 90 percent of the saturation limit was assumed as full saturation. In order to calculate saturation times, the equation was rearranged and the saturation time was solved for $\left(t_{s}\right.$ $\left.=0.90 \mathrm{a}^{2} / \mathrm{D}\right)$.

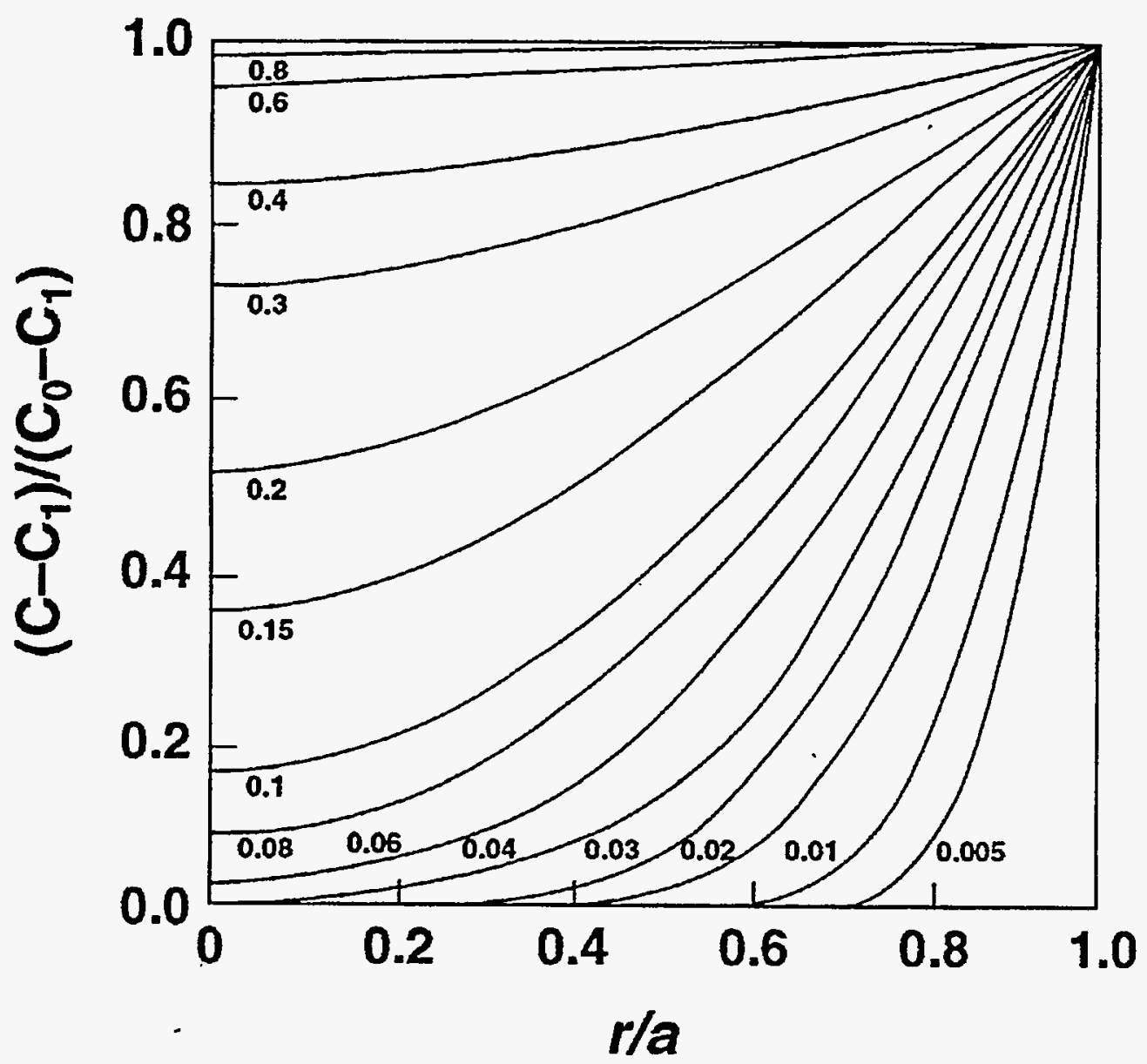

Figure 2.5. Dimensionless plot describing concentration distributions of diffusing species within a cylindrical geometry, where $\left[C-C_{1}\right] /\left[C_{o}-C_{1}\right]$ is the concentration fraction of the solubility limit and r/a is normalized radial position. The parameter $r$ is the radial position and $a$ is the radius of the solid cylinder. The values on the curves are values for $D t / a^{2}$. 


\subsection{Applications of Tantalum Carbides}

The corrosion resistive properties of carburized tantalum were discovered inadvertently. Andelin et al. ${ }^{46}$ were conducting a corrosion rate study of several metals and alloys. The scope of their investigation was to test several metals and alloys for a possible candidate to be used for containment of molten plutonium and plutonium alloys in liquid metal fuel fast nuclear reactors.

In the course of a long-term corrosion rate test, a tantalum test capsule became carburized due to backstreaming diffusion pump oil. The authors reported that the surface of the capsule appeared gold in color and that carbide inclusions were observed at the grain boundaries of the metal. The intergranular carbide inclusions retarded plutonium grain boundary penetration and improved corrosion performance four fold.

Carbide coated tantalum was first used in the actinide industry in an effort to produce ultra-pure plutonium metal. Leary and Mullins ${ }^{47}$ used carbide coated tantalum as the cathodic electrode in an effort to produce pure plutonium metal. The plutonium metal was purified to the highest purity documented ${ }^{3}$ to date. However, extended use of carbide coated electrodes was unsuccessful since the coatings spalled off after several thermal cycles.

The most current published work conducted on the tantalum-carbon system was performed by Axler. ${ }^{3,48}$ The investigation was conducted in an effort to engineer a robust corrosion resistive material impervious to severe pyrochemical processing environments and molten plutonium. In his work Axler arrived at and developed a carbon-saturated tantalum alloy (" $\mathrm{C}$-sat. Ta"). That work lead the way to the current investigation.

In Axler's investigation of the corrosion mechanisms of tantalum processing, hardware employed in pyrochemical process revealed two corrosion mechanisms: liquid plutonium attacks tantalum at the grain boundaries, and high-temperature chlorine is responsible for transgranular corrosion. It was found that plutonium migrates into the grain boundary structure and solidifies as tributaries within the tantalum grain boundaries. Within the most severely corroded conditions, it was observed that the grain morphology of the tantalum was preserved while the grain boundary material was removed. This retention of grain morphology within the reactions zone is generally associated with corrosion induced by highly reactive liquid metals. The removal of grain boundary material is illustrated in the reflective light photomicrographs presented in Figure 2.6. The dark colored material observed at the grain boundary is plutonium. 
In his investigation, Axler studied both the carbon-saturated tantalum alloy and carbide coated tantalum metal. The carbon-saturated tantalum alloy proved to be superior. The coated tantalum did not perform as well because it proved to be wetted by liquid plutonium and the coating spalled off after thermal cycling.

In the process described by Axler, bare tantalum was alloyed in three steps. First, the bare tantalum was carburizing to lay down a surface carbide coating. Second, the carbide coated metal was annealed at high temperatures to dissolve carbon from the carbide coating into the metal substrate. Upon cooling from the annealing process, the tantalum carbon solution becomes supersaturated, invoking $\mathrm{Ta}_{2} \mathrm{C}$ precipitates within the matrix of the metal substrate. Precipitate formation occurs primarily at the grain boundaries. Third, the $\mathrm{Ta}_{2} \mathrm{C}$ precipitate decorated tantalum composite is aged to invoke the optimum microstructure. After alloying, the material was machined to remove excess surface carbide.

In the experimental campaign of Axler's investigation, carbon-saturated tantalum demonstrated that it inhibited corrosion to molten salts, liquid metals, and liquid plutonium and was unaffected by thermal cycling. Several small-scale test crucibles were prepared and tested. The first test in the series of testing was thermal cycling. The material was subjected to thermal profiles of typical processing operations. After 25 thermal cycles, the carbon-saturated tantalum showed no effects due to thermal cycling. A test crucible of the alloy was subjected to molten $\mathrm{NaCl}-\mathrm{KCl}$ equimolar salt, $\mathrm{CaCl}_{2}$, calcium metal, and liquid plutonium metal. Repeated testing revealed no reaction zones were present. A test crucible was subjected to plutonium and salt containment at high temperature. Another test crucible was loaded with plutonium and heat soaked for 200 hours at about $765^{\circ} \mathrm{C}$. Neither crucible showed indications of wetting by liquid metal. A small quantity of plutonium was found on the wall of the crucibles due to physical adhesion. The plutonium was removed, and clean phase disengagement was metallographically confirmed.

The most severe plutonium processing environment was used to test the in-service performance of the alloy. Bare tantalum and the carbon-saturated tantalum alloy were subjected to $99.5 \%$ pure chlorine gas, molten $\mathrm{CaCl}_{2}, \mathrm{CaO}$, calcium metal, and liquid plutonium at $850^{\circ} \mathrm{C}$ for $1600 \mathrm{~min}$. The only evidence of material interactions with the carbon-saturated tantalum alloy was transgranular corrosion due to the chlorine gas. In a comparison of corrosion in the most severely attacked regions, the carbon-saturated tantalum alloy showed a greater than $60 \%$ improvement in retained cross-sectional thickness. Thus, the improvement in corrosion resistance was attributed to both grain boundary carbide occupancy and interstitial carbon. 

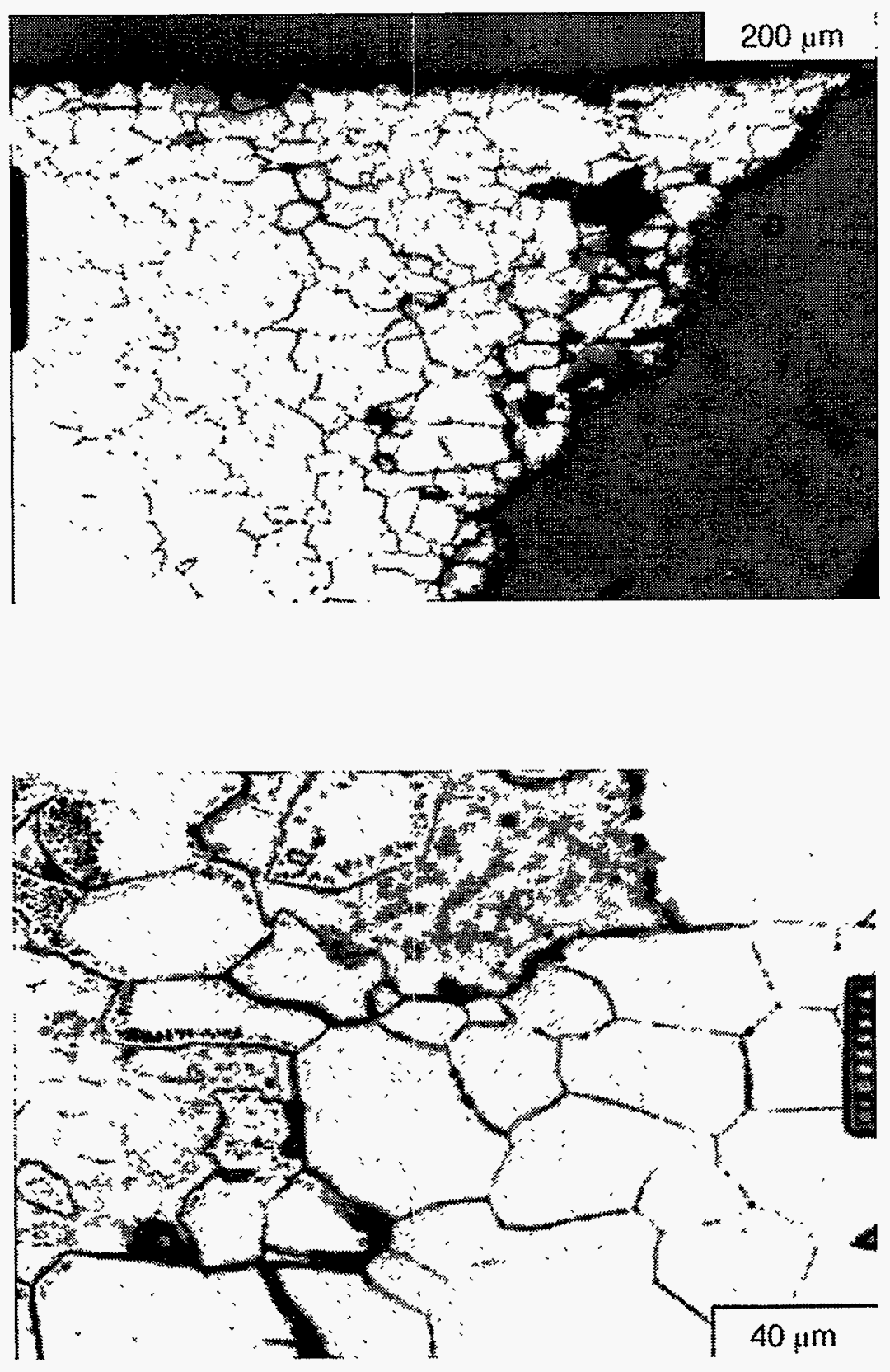

Figure 2.6. Reflective light photomicrographs of the effect of molten plutonium on tantalum metal. The dark colored material observed at the grain boundary is plutonium. It can be observed that the tantalum grain morphology was preserved. Also, grains of tantalum were removed. The removed tantalum grains are the artifacts observed in the solidified plutonium metal in the left region of the photomicrograph. 


\subsection{Experimental Procedure}

\subsection{Experimental Methodology}

A simple but telling approach was taken to probe the interactions of two complex phenomena: carbide coating growth and concurrent dissolution of carbon into the tantalum substrate. To investigate the effects of the phenomena of carbon dissolution during the carburization process on surface carbide growth, a series of multiple specimen carburization runs were performed. Rod specimens of bare (carbon-free) tantalum and pre-carbon-saturated tantalum were carburized simultaneously in the same media.

The pre-carbon-saturated specimen was used to establish a bench mark for carbide growth. By using a fully carbon saturated specimen, the thickness of surface carbide coatings could be measured without the effects of dissolving carbon into the tantalum matrix. The latter enabled a comparison to be made between coating thickness achieved with and without the effects of dissolving carbon into the metal substrate.

The kinetic rate of carbon diffusion in tantalum is reported as an average bulk diffusion rate. The kinetic rate was determined empirically. However, the diffusion of carbon into the tantalum substrate depends on carbon concentration and varies as the concentration changes. As the concentration of the carbon in the tantalum substrate increases, the rate of diffusion decreases. At the inception of this experimental campaign, the author theorized that if the competing phenomena of carbon diffusion from the coating was responsible for the observed deficiencies in the carbide coating growth, the coating growth rates should more closely follow the model when the carbon concentration in the substrate increases and the diffusion rate decreases. Thus, to further probe the interaction of the competing phenomena, bare tantalum rod specimens of different diameters were carburized simultaneously.

\subsubsection{Carburization Time Selection}

The models for carbide coating growth and diffusion in an effectively infinitely long cylinder were taken in concert with observed carbide coating growth data to arrive at an optimum carburization time. Data on actual carbide coating thicknesses reported in an investigation by $\mathrm{Axler}^{3}$ was used as a reference of coating growth.

In his work, Axler reported observed carbide coating thicknesses ranging from 24 to 62 percent of the theoretical thicknesses for a carburization temperature of $1800^{\circ} \mathrm{C}$ and carburization 
times of 11 to 20 hours. Normalized values of observed coating thickness reported in that study are plotted as a function of time in Figure 3.1. Observed thickness values are normalized over the theoretical thickness values to provide a percent of theoretical value. It is observed that the disparity in actual growth decreases with increasing carburization times. This would appear to imply that as carburization time and the carbide layer thickness increases, the fixed quantity of surface carbide that can be dissolved becomes a smaller fraction of the theoretical carbide coating calculated. Although the data is limited, it is apparent there is a break in the data where saturation of the tantalum matrix is assumed to have occurred. The time regime in which this break occurs is in reasonable agreement with the diffusion kinetics of the specimens tested. This would tend to support the theory that there are two competing mechanisms.

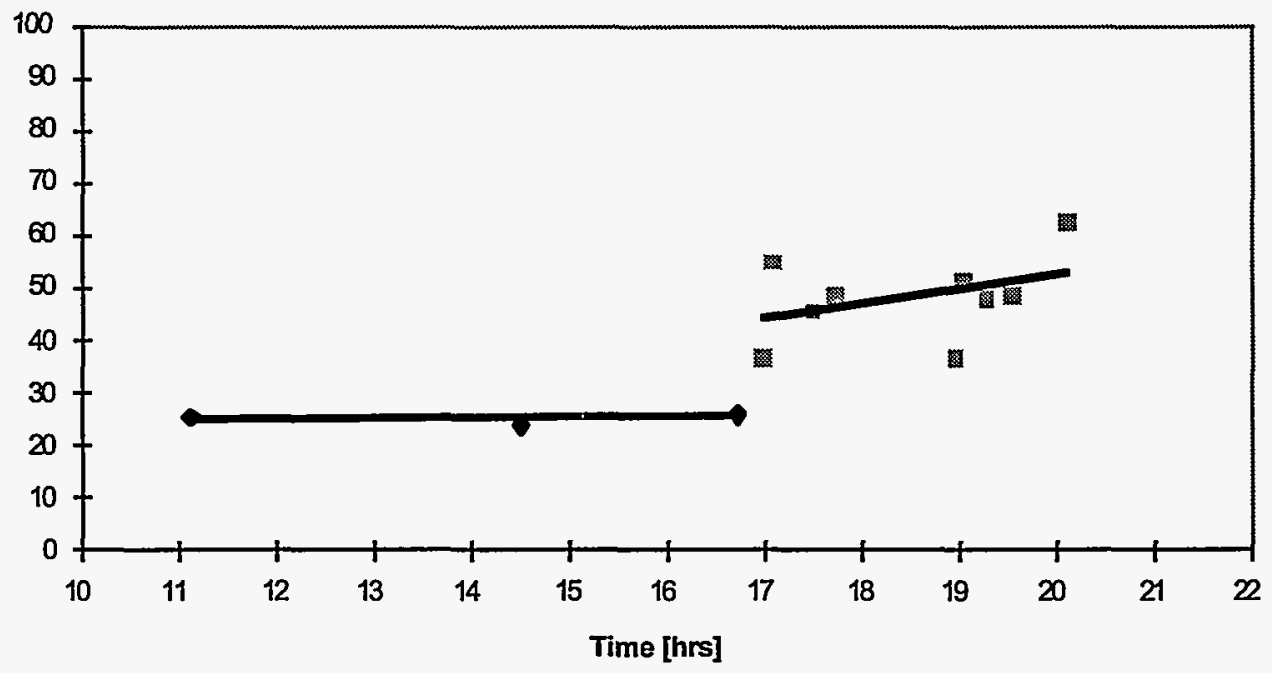

Figure 3.1. The above data was extracted from Axler's study. From this data it is evident that actual carbide growth more closely follows the model as carburization times increase. This trend would tend to support the theory that carbide growth will accelerate as the matrix of Ta becomes carbon saturated. In the data presented above it appears that there is a break between two data sets: those which indicate carbide growth before matrix saturation and those after matrix saturation. The time regime in which this break occurs is in reasonable agreement with the diffusion kinetics of the coupons tested. However, the degree of conclusiveness associated with the observed break in data is limited by the scant availability of data at the lower carburization times.

Taking the models for diffusion in an effectively infinitely long cylinder in concert with carbide growth rate data, it was determined that a total of 1.8 hours is the carburization time required to coat the tantalum substrate surface with the maximum amount of carbon that can be accommodated in solid solution at $1700^{\circ} \mathrm{C}$ in a $0.291 \mathrm{~cm}$ diameter rod. The carbide growth model predicts that after 1.8 hours of carburization the coating thickness should be 16 microns. However, from Axler's data it was found that actual coating thickness measured about 25 percent 
of the predicted value for this selected time regime. The carbide coating growth model predicts that at 25 hours of carburization the coating should be 59.5 microns thick. From Axler's study it is shown that the discrepancy in observed coating growth and calculated growth decreased with increasing carburization times; after 25 hours of carburization, the discrepancy between observed and predicted carbide growth was approximately 50 percent. Therefore, to achieve a coating thickness of $\gg 30$ microns, a value of $\gg 60$ microns would have to be targeted ( 25 hrs @ $\left.1700^{\circ} \mathrm{C}\right)$.

Upon designing the bare versus presaturated tantalum experiment, it was decided that bare tantalum rods would be used as test specimens. Test specimen rods of $0.291 \mathrm{~cm}$ nominal diameter and $0.635 \mathrm{~cm}$ nominal diameter were selected. It was calculated that the $0.291 \mathrm{~cm}$ nominal diameter bare tantalum rods would reach full carbon saturation after 16 hours of carburization. Thus, the rods would be carburized while fully saturated for 9 hours. It was calculated that it would take 76 hours to fully saturate $0.635 \mathrm{~cm}$ nominal diameter rods. Thus, the amount of carbon that would be dissolved from the coatings on the $0.635 \mathrm{~cm}$ diameter rods should be greater than that of the smaller diameter rods. It was expected that larger diameter test specimens should exhibit a greater deficiency in carbide coating thicknesses.

Based on theoretical calculations for carbide coating growth and diffusion in an effectively infinitely long cylinder, it was calculated that the number of moles of carbon soluble in the metal matrix of a $0.291 \mathrm{~cm}$ diameter bare tantalum rod amounts to an equivalent of 16 microns of carbide coating. Thus, if diffusion of carbon into the metal substrate was the only contributing factor to the observed carbide layer deficiencies and a coating thickness of 60 microns was targeted, a 16 micron difference in coating thickness was expected between the bare and presaturated rods of $0.291 \mathrm{~cm}$ nominal diameter. It was also expected that if diffusion of carbon into the metal matrix was the only factor contributing to the observed coating thickness deficiencies, a measure of weight gain would show that the mole numbers of carbon missing from the coating could be accounted for in the substrate.

\subsection{Materials and Equipment}

All tantalum used in this experimental campaign was acquired from Fansteel. All tantalum acquired was from the same stock. An extensive elemental analysis was conducted at Los Alamos National Laboratory to determine metallic composition. Results of the elemental analysis and batch analysis provided by Fansteel are presented in Table 3.1. The results of both analyses were in good general agreement. The stock of tantalum is of $99.9 \%$ minimum purity. 
Tantalum used in this experimental campaign was purchased in the form of $0.318 \mathrm{~cm}$ and $0.648 \mathrm{~cm}$ nominal diameter rod stock. The rods were manufactured by arc-casting and then annealing.

The carbon used as the packed-bed media was purchased from Darco American Norit Company, Inc. Darco G-60 Powder Activated Carbon is of premium purity grade activated carbon. The particulate size was such that $90 \%$ will pass through 100 mesh and $60 \%$ will pass through 325 mesh screens.

A Centorr High-Temperature resistive heating furnace was used in the processing of tantalum rod specimens. The furnace was evacuated via a Stokes Microvac 148-10 mechanical pump. Process temperatures were measured using a " $C$ " type thermocouple read by a UDC 3000 Honeywell temperature controller. The furnace was equipped with a second independent " $C$ " type thermocouple that was read by a UDC 2000 Honeywell controller.

Weight measurements were performed on a Mettler AT201 precision balance. The precision balance was calibrated to measure accurately to 10 micrograms.

All metallography performed on test specimens were conducted on a Leco 300 optical metallograph. Image analysis images were taken with a 4.2 Mega-Plus Kodak camera and captured with 1.44VDM-F software on a Macintosh Quadra 950 computer. Image analysis was conducted via Adobe Photoshop 2.5 on the Quadra 950.

\subsection{Preparation For Experimentation}

Before the bare versus pre-carbon-saturated carburization experiments could be conducted, several processing issues required investigation. The foundation of the current investigation was built on empirical data reported in a previous investigation. ${ }^{3}$ In that investigation carbide coatings were produced via gas phase carburization. In the current investigation, carburization was conducted via packed-bed carburization. Thus, the equivalence of the two carbide coating processes required evaluation. Also, a variation on the traditional packed-bed carburization of the tantalum-carbon system was employed. Thus, the packed-bed method employed required evaluation. These and other processing details were addressing before the main experimental campaign was constructed. 
Table 3.1. Elemental analysis conducted at Los Alamos National Laboratory on the metallic composition of tantalum stock used in this experimental campaign. Also included is the chemical analysis provided by the manufacture, Fansteel.

\begin{tabular}{|c|c|c|c|}
\hline Element & $\begin{array}{c}\text { Level [ppm] } \\
\text { LANL] } \\
\text { Fansteel }\end{array}$ & Element & $\begin{array}{c}\text { Level }[\mathrm{ppm}] \\
\text { LANL } \\
\text { Fansteel }\end{array}$ \\
\hline Aluminum & N/A $/<10$ & Neodymium & $<500$ \\
\hline Antinomy & 2 & Nickel & 94 \\
\hline Arsenic & $<10$ & Niobium & 8 \\
\hline Barium & $<500$ & Nitrogen & $\mathrm{N} / \mathrm{A} / 24$ \\
\hline Beryllium & $<2$ & Oxygen & N/A / 59 \\
\hline Bismuth & $<1$ & Palladium & $<1$ \\
\hline Cadmium & $<1$ & Platinum & $<5$ \\
\hline Calcium & $\mathrm{N} / \mathrm{A} /<10$ & Praseodymium & $<100$ \\
\hline Carbon & N/A / 14 & Rhenium & $<200$ \\
\hline Cerium & $<200$ & Rhodium & $<100$ \\
\hline Cesium & $<200$ & Rubidium & $<1$ \\
\hline Chromium & $<10$ & Ruthenium & $<1$ \\
\hline Cobalt & $<1$ & Samarium & $<500$ \\
\hline Copper & 15 & Selenium & $<20$ \\
\hline Dysprosium & $<200$ & Silicon & $\mathrm{N} / \mathrm{A} /<10$ \\
\hline Erbium & $<200$ & Silver & $<1$ \\
\hline Europium & $<200$ & Strontium & $<10$ \\
\hline Gadolinium & $<500$ & Tellurium & $<10$ \\
\hline Gallium & $<500$ & Terbium & $<100$ \\
\hline Germanium & $<4$ & Thallium & $<500$ \\
\hline Hafnium & $<2$ & Thorium & $<100$ \\
\hline Hydrogen & N/A $/<5$ & Thulium & $<100$ \\
\hline Iron & N/A / 50 & Tin & 2 \\
\hline Lanthanum & $<100$ & Titanium & $<5$ \\
\hline Lead & 5 & Tungsten & 11 \\
\hline Lithium & $<2$ & Uranium & $<1$ \\
\hline Lutetium & $<100$ & Ytterbium & $<500$ \\
\hline Manganese & $<5$ & Zinc & $<7$ \\
\hline Magnesium & $<30$ & Zirconium & 6 \\
\hline Mercury & $<7$ & Tantalum & Balance \\
\hline Molybdenum & $<1$ & & \\
\hline
\end{tabular}

\subsubsection{Packed-Bed Carburization}

In the current investigation packed-bed carburization was employed as the method of carburization. The technique involved using fine particulate powder carbon as the carbonaceous media. The carbon powder and tantalum rod specimens were contained within a graphite crucible during carburization. 
To initiate the carburization run, the packed-bed carbon media and graphite containment crucible were baked-out to remove humidity and any organic contaminants that may have collected. The bake-out process consisted of placing the graphite containment crucible and packedbed carbon media into the furnace and evacuating the furnace chamber down to $2.0 \times 10^{-2}$ torr. Then the chamber was backfilled to slightly above atmospheric pressure with argon and evacuated again to $2.0 \times 10^{-2}$ torr. The backfill and purge process was performed three times before starting the temperature ramp.

The temperature ramp was initiated when the final chamber purge reached $2.0 \times 10^{-2}$ torr. The furnace was ramped up to $1700^{\circ} \mathrm{C}$ at $20^{\circ} \mathrm{C}$ per minute and held at $1700^{\circ} \mathrm{C}$ for one hour. This is the same ramp rate and soak temperature employed in the carburization of all test specimens. At the end of the 1 hour soak, power to the furnace heating elements was halted. The furnace cooled to $1400^{\circ} \mathrm{C}$ in approximately 1.5 seconds. Upon completion of the bake-out procedure the furnace chamber was held under $2.0 \times 10^{-2}$ torr vacuum awaiting the introduction of the experimental subject specimens. Both the bake-out and carburization procedures were conducted with the furnace chamber under continuous evacuation in order to keep the carbon media and tantalum parts from reacting with any species of air, mainly oxygen. A photograph of the graphite containment crucible and packed-bed carbon media are presented in Figure 3.2.

Immediately before introduction of the experimental subject specimens, the specimens were sonic cleaned in ethyl alcohol for five minutes and precision weighed. The furnace was backfilled with argon to atmospheric pressure, and the specimens were placed into the packedbed carbon media. The crucible was briefly vibrated by hand to ensure uniform packing of the carbon powder around the test specimens. Then the same purge and backfill procedure described above was followed. The bare tantalum and carbon-saturated rod specimens were ramped-up at $20^{\circ} \mathrm{C}$ per minute to $1700^{\circ} \mathrm{C}$ and held for a precalculated carburization time. At the end of the carburization soak, power to the furnace heating elements was halted, and the furnace chamber was allowed to cool freely. Upon cooling, the specimens were removed from the packed-bed media and immediately sonic cleaned in ethyl alcohol for one minute and precision weighed.

In general, the packed-bed carburization technique used is a unique modification of past practices. The technique was developed at Los Alamos National Laboratory by Peter Lopez. ${ }^{49}$ In his investigation, Lopez was searching for a carburization method compatible with existing furnace equipment available within the organization, in order to investigate the feasibility of carburizing and saturating tantalum processing hardware in-house. The current author became involved on this project a short time after Lopez's initial investigations. 


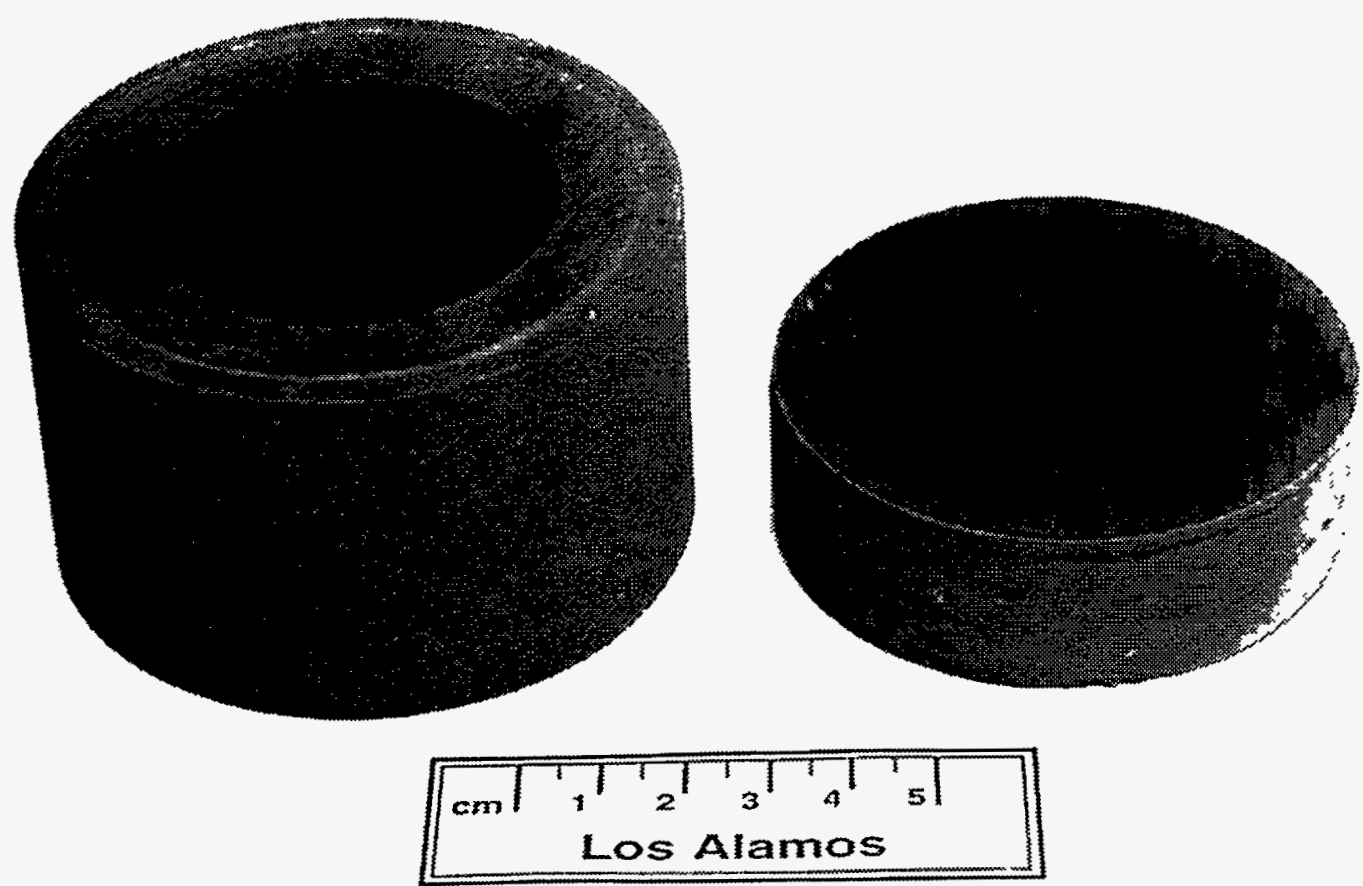

Figure 3.2. Graphite containment crucible and lid employed to contain packed-bed carbon media and subject tantalum specimens during carburization.

In past studies of the tantalum-carbon system where packed-bed carburization was employed, carburization was conducted in a hydrogen/inert gas mixture atmosphere. The hydrogen atmosphere was introduced as a transport medium. The hydrogen reacts with the carbon to form hydrocarbons which in turn react with the metal surface. The requirement for a hydrogen atmosphere was felt especially necessary for processing temperatures below $2000^{\circ} \mathrm{C}$ where direct vaporization of carbon to the metal surface was believed unattainable.

At the inception of Lopez's investigations the use of a hydrogen atmosphere was undesirable. The addition of a hydrogen atmosphere introduces several complications to the packed-bed carburizing scheme. First, it would be difficult to control a uniform flow of hydrogen/inert gas flow through the bed of the carbon without designing complicated containment fixtures and gas delivery lances. The selection of tantalum processing hardware that could be carburized would greatly be limited by the requirement for complicated fixturing. Furnace efficiency would also decrease due to the increase in thermal mass of the fixturing. The second and probably most important complication associated with the presence of hydrogen is tantalum's solubility of hydrogen. Embrittlement of the metal leads to undesirable mechanical property degradation. 
It was determined that a key to efficient packed-bed carburization without the addition of hydrogen gas was to keep the activity at the metal's surface at unity at the initiation of carburization. One way to accomplish this was to put carbon in direct contact with the surface of the metal. Thus, a carbon powder of fine particulate size was selected to increase the metal's surface area in contact with carbon at the initiation of the carburization process.

\subsubsection{Preparation of Carbon-Saturated Specimens}

The carbon-saturated specimens employed in this study were prepared in a previous study ${ }^{3}$ by Axler. The specimens were processed at the Basic Industrial Research Laboratory (BIRL) of Northwestern University. The specimens were prepared via gas phase carburizing and subsequent thermal processing to achieve saturation. The tantalum processed in Axler's study is of the same $0.318 \mathrm{~cm}$ diameter rod stock as that used in the current study.

A 4.2 percent methane in argon gas atmosphere was used as the carburizing agent. The gas mixture was flowed through the furnace at $250 \mathrm{sccm}$. The specimens were carburized at $1800^{\circ} \mathrm{C}$ for a period of time sufficient to grow a carbide surface layer capable of providing the necessary carbon for full saturation of the substrate volume.

Subsequent to carburization, the specimens were thermally treated to dissolve carbon into the tantalum substrate volume. Upon completion of thermal treatment the carburized/saturated rod specimens were sectioned and metallography was performed. Image analysis was employed to measure $\mathrm{Ta}_{2} \mathrm{C}$ precipitate volume percent within the volume of the rod. $\mathrm{The}_{2} \mathrm{C}$ precipitate volume percent was used to calculate carbon content. Image analysis was performed on the same equipment employed in the current study. The volume of the rod specimens was found to be fully saturated at 0.997 at.\% carbon at the $1800^{\circ} \mathrm{C}$ saturation temperature.

The author chose to use the specimens saturated in that previous study because of their extensive characterization. The carbon content was measured via digital optical imaging. The results of digital optical imaging were confirmed by chemical analysis.

A second reason for using the specimens saturated at $1800^{\circ} \mathrm{C}$ was that at $1700^{\circ} \mathrm{C}$, the current experimental campaign's carburizing temperature, the specimen will be supersaturated. Referring to Figure 2.4 it can be observed that the solubility limit at $1700^{\circ} \mathrm{C}$ is approximately 0.700 at.\% carbon in tantalum. The solubility limit measured in Axler's was 0.997 at. $\%$ carbon in tantalum at $1800^{\circ} \mathrm{C}$. 
The carbon-saturated specimens acquired from the previous study had further been aged, at temperature between 1200 and $1400^{\circ} \mathrm{C}$, to investigate precipitate formation kinetics. Using diffusion kinetics and the known distance between precipitates, the author calculated that at $1700^{\circ} \mathrm{C}$ it will take a fraction of a second for the volume of tantalum to be fully saturated in a supersaturated phase of solid solution carbon in tantalum and $\mathrm{Ta}_{2} \mathrm{C}$ precipitates. Therefore, the saturated solid solution was assumed to be present by the time the sample reached the $1700^{\circ} \mathrm{C}$ dwell temperature.

\subsubsection{Specimen Surface Preparation}

Since carbide layer growth is a function of surface area, a constant uniform surface finish was desired on both specimens. Thus, the surfaces of all specimens were machined to a \#32 machine finish before carburization. In the case of the carbon-saturated specimens acquired from the previous study, the carbide coating was first removed. In order to remove the carbide coating, 0.025 to $0.030 \mathrm{~cm}$ was machined off the diameter of the specimens. A unique diamondtipped grinding tool developed at Los Alamos National Laboratory was used to machine the extremely hard carbide coating. An equivalent amount of material was machined off the surface of the bare tantalum rods during the surface finishing process. Thus, the diameter of the smaller diameter rods was nominally $0.291 \mathrm{~cm}$ before caburization. The nominal diameter of the larger diameter rods carburized was $0.635 \mathrm{~cm}$ before carburization.

The bare tantalum rods were sectioned with a diamond cutting wheel on a low-speed metallographic saw. The rods were cooled with water during cutting. The smaller diameter bare tantalum rods were cut to a nominal length of $2.54 \mathrm{~cm}$. The larger diameter bare tantalum rods were cut to a nominal length of $5.00 \mathrm{~cm}$. The length and diameter of the rods were measured and recorded for use in the analysis.

\subsubsection{Preliminary Packed-Bed Carburization Studies}

At the commencement of this study a series of preliminary carburizations were conducted in order to evaluate the feasibility of using packed-bed carburization as a viable caburization method. The first series of experiments were conducted in order to determine if carbide coating results similar to Axler gas phase carburization work could be achieved. The packed-bed technique described earlier was refined during the course of these initial carburization tests. 
Two carburization runs at $1700^{\circ} \mathrm{C}$ were conducted with 12 and 18 hour carburization times. These carburization times were in the same time regime as some of those conducted by Axler. Tantalum rods of $0.291 \mathrm{~cm}$ nominal diameter were carburized. Results of these carburization runs are presented in Table 3.2. The test specimens prepared in Axler's study were prepared via gas phase carburization in a methane/argon atmosphere as discussed previously.

Table 3.2. Carbide coating thickness recorded during the preliminary evaluations of the packed-bed carburization technique employed in this investigation. Calculated coating thicknesses are based on growth rates reported by Krikorian.

\begin{tabular}{||c|c|c|c||c|c|c|c|}
\hline \multicolumn{4}{|c||}{ Current Study [1700 } & \multicolumn{4}{c|}{ Axler Study [1800 } \\
\hline \hline $\begin{array}{c}\text { Time } \\
{[\mathrm{hrs}]}\end{array}$ & $\begin{array}{c}\text { Obs. } \\
{[\mathrm{cm}]}\end{array}$ & $\begin{array}{c}\text { Calc. } \\
{[\mathrm{cm}]}\end{array}$ & $\begin{array}{c}\text { Obs/Cal } \\
\text { c }\end{array}$ & $\begin{array}{c}\text { Time } \\
{[\mathrm{hrs}]}\end{array}$ & $\begin{array}{c}\text { Obs. } \\
{[\mathrm{cm}]}\end{array}$ & $\begin{array}{c}\text { Calc. } \\
{[\mathrm{cm}]}\end{array}$ & $\begin{array}{c}\text { Obs/Cal } \\
\mathrm{c}\end{array}$ \\
\hline 12 & 0.0030 & 0.0041 & $73 \%$ & 11.13 & 0.0016 & 0.0063 & $25 \%$ \\
\hline 18 & 0.0037 & 0.0051 & $73 \%$ & 17.75 & 0.0038 & 0.0079 & $48 \%$ \\
\hline
\end{tabular}

As can be observed in Table 3.2, it was found that the packed-bed carburization technique employed in the current investigation produced carbide coating thicknesses closer to the calculated thicknesses than those produced in the investigation by Axler. Thus, the packed bedcarburization technique was deemed suitable.

\subsubsection{Microprobe Analysis of Tantalum Carbide Coatings}

Electron probe microanalysis was conducted on a typical carburized specimen in order to characterize the composition of the carbide coating formed during the packed-bed carburization processing. The Energy Dispersive Spectroscopy (EDS) capability of a CAMECA Model MBX electron probe microanalysis/scanning electron microscopy (EPMA/SEM) instrument was employed in the analysis. TASK-8 software was used to support EDS. This software was used because of its utility in quantitative analysis of materials composed of elements with large differences in atomic numbers.

EDS was conducted on the carbide coating starting from the outermost layer of the carbides $(\mathrm{TaC})$ and scanning in through the metal rich intermediate layer $\left(\mathrm{Ta}_{2} \mathrm{C}\right)$ on into the metal substrate. Results of the electron probe microanalysis revealed that the composition of the carbides achieved via packed-bed carburization are in good agreement with those reported. 
Results of the scan can be observed in Figure 3.3 as a plot of the composition in atomic percent versus position of the scan. The analysis of the $\mathrm{TaC}$ phase illustrated a presence of the $\mathrm{TaC}$ phase existence over its compositional range of homogeneity. The analysis of the $\mathrm{Ta}_{2} \mathrm{C}$ phase revealed the two to one atomic ratio expected for $\mathrm{Ta}_{2} \mathrm{C}$.

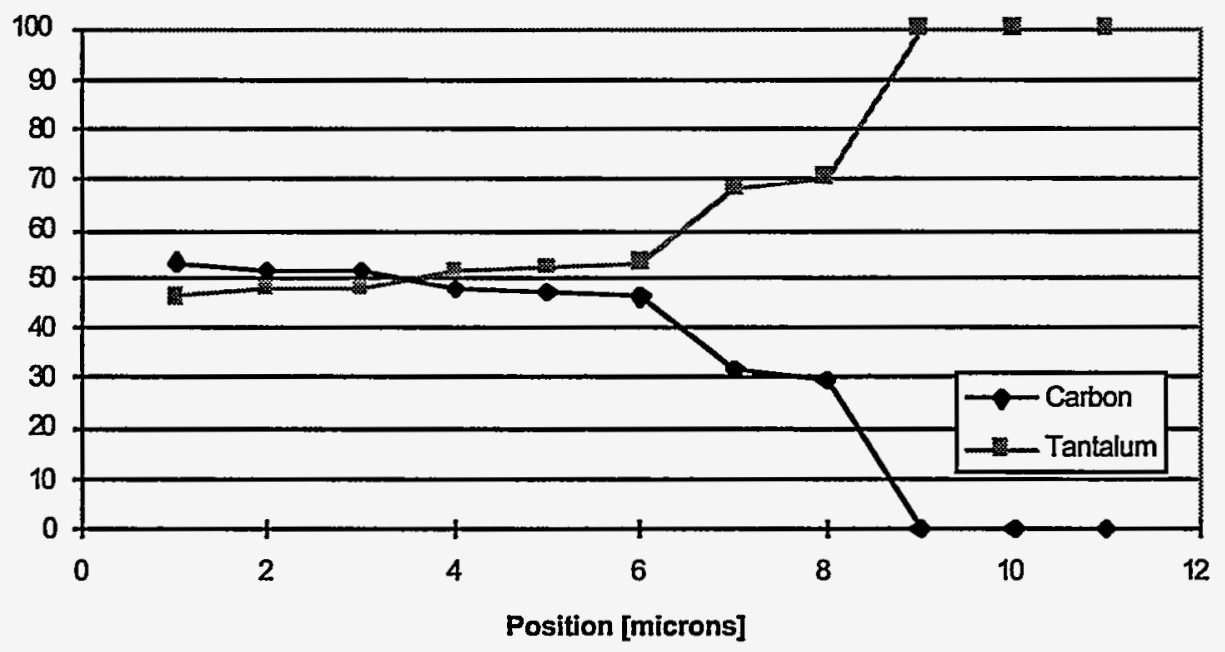

Figure 3.3. Results of electron probe microanalysis Energy Dispersive Spectroscopy scan of typical carbide coating layers produced via packed-bed carburization. The scan reveals that coatings are consistent with that which would be expected and coincide with data presented in the tantalum-carbon binary phase diagram.

\subsection{Metallographic Preparation of Carbide Coated Specimens}

All carburized tantalum rod specimens evaluated for carbide coating thickness were metallographically prepared in the same fashion. The rods were polished down to $1 / 4 \mathrm{~mm}$ diamond paste polish and stain etched. A highly refined etching process developed by Ramiro Pereyra ${ }^{50}$ of Los Alamos National Laboratory was employed. The etching process developed was an electro-etchant process. It involves etching the carburized specimens in a solution of $\mathbf{3 0}$ percent $\mathrm{KOH}$ in water with $35 \mathrm{VDC}$ applied.

The etchant and etching process were developed in an investigation of carbide precipitation within the tantalum substrate. The etching process obviates the appearance of mechanical artifacts which could be mistaken for carbide inclusions. The etching process offers a greater visual contrast between the carbide coating and the tantalum metal than traditional metallographic preparations. This high degree of contrast makes carbide coating thickness measurement possible by digital optical imaging. 


\subsection{Carbide Coating Thickness Measurement}

In past studies, carbide layer thicknesses have been measured physically off reflective light photomicrographs with either a ruler or optical lens filar micrometer. This method involves making many measurements at different locations on several micrographs and calculating the average carbide thickness. As can be noted in micrographs of carbide layers throughout this document, the $\mathrm{Ta}_{2} \mathrm{C} / \mathrm{Ta}$ boundary is not completely uniform. Therefore, this measurement method involves measuring topography which can induce errors. In an effort to alleviate the tedious nature and uncertainties associated with measuring carbide layer thickness in this study, a digital imaging analysis procedure was developed to measure carbide thickness.

The digital imaging analysis carbide measuring technique developed in this work is a novel approach which apparently has not been reported previously in a reviewed literature. A brief description of the coating thickness measurement follows. For a detailed step-by-step description of the procedure, refer to Appendix A.

The contrast of carbide to tantalum metal in metallographic specimens in the stain-etched condition is the feature which makes image analysis possible. Image analysis employs the gray scales discriminator feature of Adobe Photoshop. When the image is analyzed as a gray scale image, the user may select a threshold value of gray which Adobe Photoshop considers to be black. All lighter shades of gray are considered to be white. A selected area can be mapped for black and white distinction. Adobe Photoshop has a feature which provides the user with the number of black pixels and white pixels in the mapped area.

The threshold values selected were such that the carbide layers were determined to be white. The tantalum metal and mounting epoxy were determined to be black. As can be observed in Figure 3.4, a rectangular area of exact length was mapped. Typically, a rectangular area of 400 pixels by 600 pixels was mapped. The rectangular area selected was such that the length of rectangle was parallel to the length of the carbide coating. In both digital optical carbide coating measurement scans, the uppermost gray regions are epoxy. The lower gray regions are the tantalum substrate. And, the white bands running across the scans are the carbide coating layers.

Upon mapping, the software was used to determine the number of white pixels and the number of black in the mapped area. The number of white pixels was the area of carbide present in the mapped selection. Knowing the length mapped and the area of carbide, the equation for 
the area of a rectangle was used to calculate a normalized carbide layer width in pixels. Knowing the number of pixels in a unit length and the magnification of the optical image, the width in pixels was converted to length in micrometers. Four measurements per specimen were taken to determine the average carbide layer thickness. 

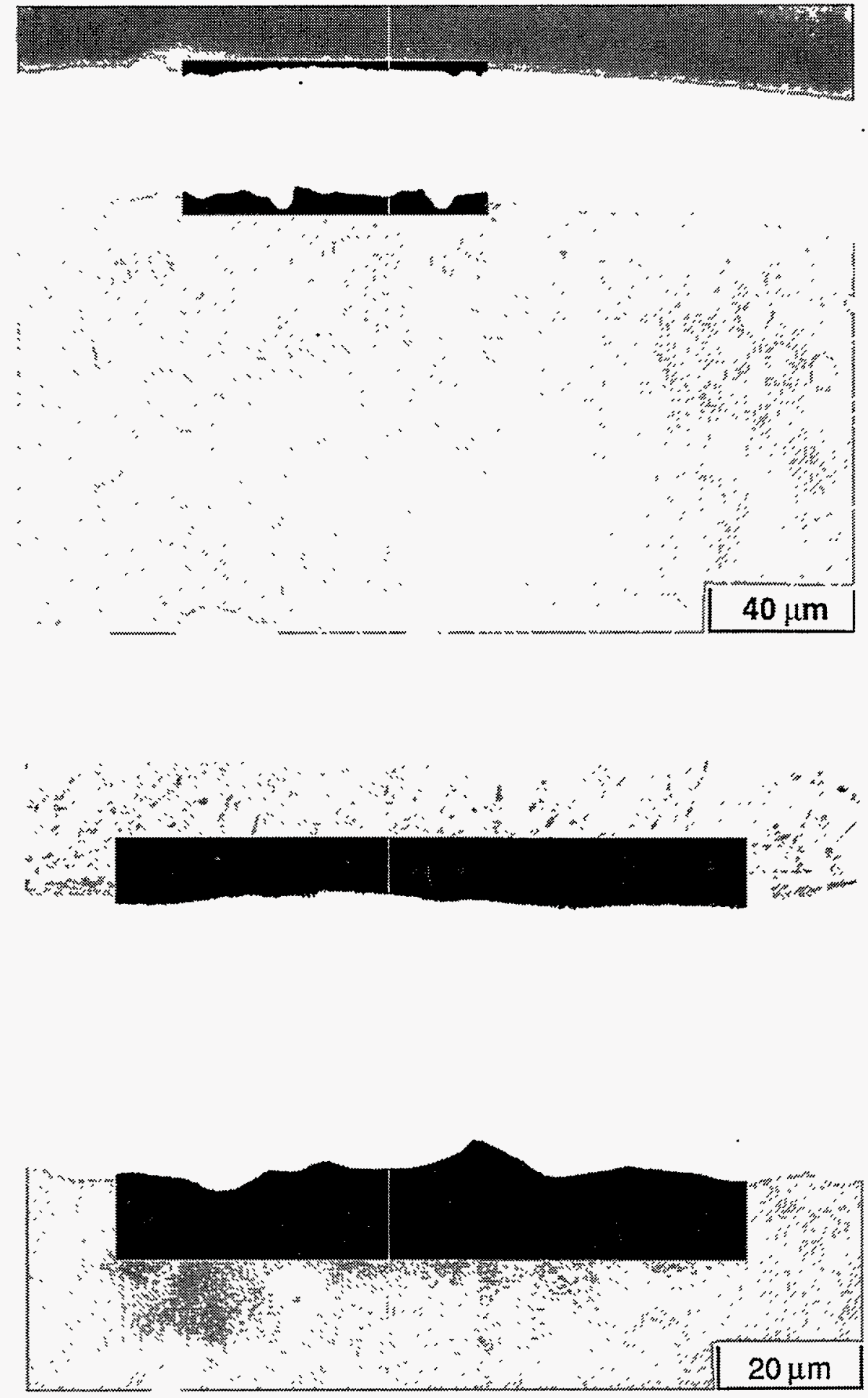

Figure 3.4. Adobe Photoshop digital images of typical digital optical carbide coating thickness measurement scans. The rectangular areas mapped are 400 pixels by 600 pixels. In both digital optical carbide coating measurement scans, the uppermost gray regions are epoxy. The lower gray regions are the tantalum substrate. The white bands running across the scans are the carbide coating layers. 


\subsection{Results and Discussion}

\subsection{Chamber Atmosphere Study}

The chamber atmosphere test consisted of one carburization run. Two tantalum rod test specimens were thermally processed simultaneously. One test specimen was placed in the packed-bed carbon media. The other test specimen was placed in a tantalum crucible absent of carbon. The test specimens were thermally processed for 25 hours at $1700^{\circ} \mathrm{C}$.

Metallography and coating thickness measurements were conducted on the test specimens. The same was conducted on a third test specimen of bare tantalum which was not thermally processed. The latter was done to in order to verify that no detectable coating was present on the metal stock in the bare state.

A reflective light photomicrograph of the bare tantalum specimen in the as-received condition is presented in Figure 4.1. There is no evidence of any coating present on the metal in the bare state. This is consistent with the chemical analysis report.

A reflective light photomicrograph of the test specimen which was thermally processed in the packed-bed media is presented in Figure 4.2. A carbide coating of 44 microns was measured.

A reflective light photomicrograph of the test specimen thermally processed in the absence of the packed-bed carbon media is presented in Figure 4.3. A carbide coating of 4 microns was measured. The author is confident that the observed coating was tantalum-carbide because the test specimen appeared gold in color upon removal from the furnace. The gold color which was observed is typical of $\mathrm{TaC}$ coatings. Tantalum oxide coatings are blue.

Over the experimental campaign, it was observed that the fine particulate carbon employed profusely migrated throughout the furnace chamber if not properly contained. During some of the initial carburization trials, the fine particulate carbon was completely extracted from the containment crucible. It was determined that during initial pump-down and purge procedure, the fine particulate carbon was floated throughout the furnace when the atmosphere was being removed. This problem was remedied by placing some weight on top of the graphite crucible's lid. A minimum weight was applied because it was a concern that oxygen may be trapped within the graphite crucible. A small amount of graphite was always observed to escape the graphite crucible during carburization runs. It was the author's belief that the test specimen thermally 
processed in the absence of the carbon packed-bed media was carburized by carbon particulate which floated into the open tantalum crucible that contained the test specimen. Thus, it was determined that the furnace was sufficiently free of oxygen during carburization, and the problems associated with the presence of oxygen during carburization were eliminated.

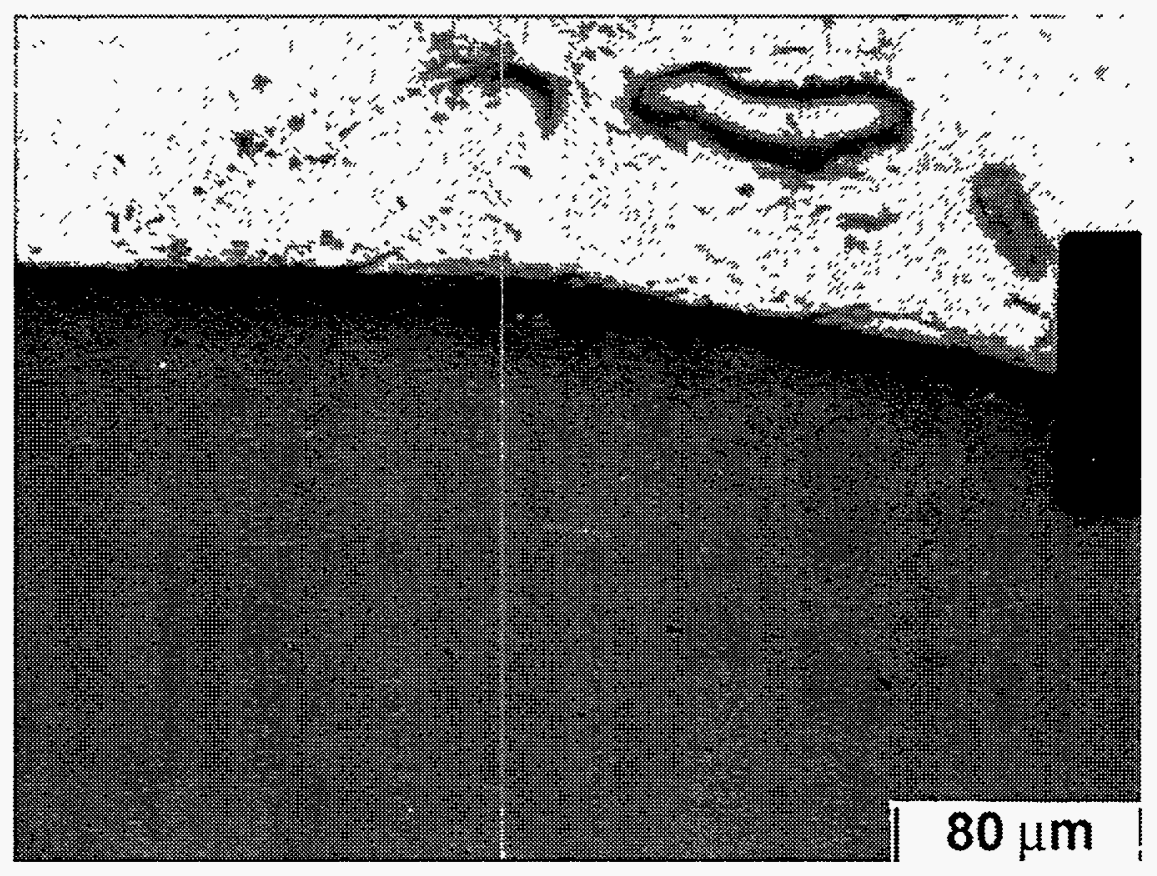

Figure 4.1. Reflective light photomicrograph of tantalum in the as-received bare condition. The lower darker region is the tantalum. 


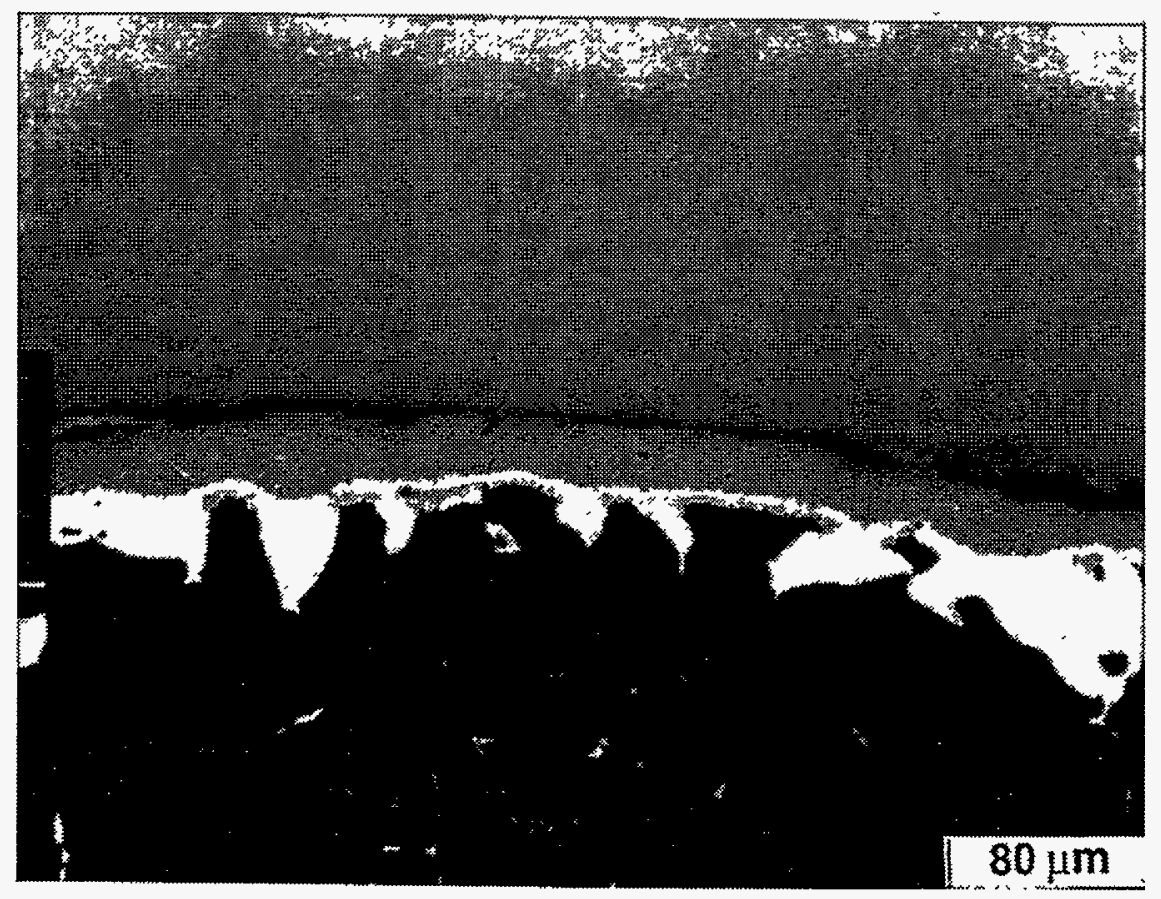

Figure 4.2. Reflective light photomicrograph of tantalum test specimen carburized for 25 hours at $1700^{\circ} \mathrm{C}$ in the packed-bed carbon media. The upper layer is $\mathrm{TaC}$ and the lower layer is $\mathrm{Ta}_{2} \mathrm{C}$. The lower darker region is the tantalum substrate. The total carbide coating thickness measured to 44 microns.

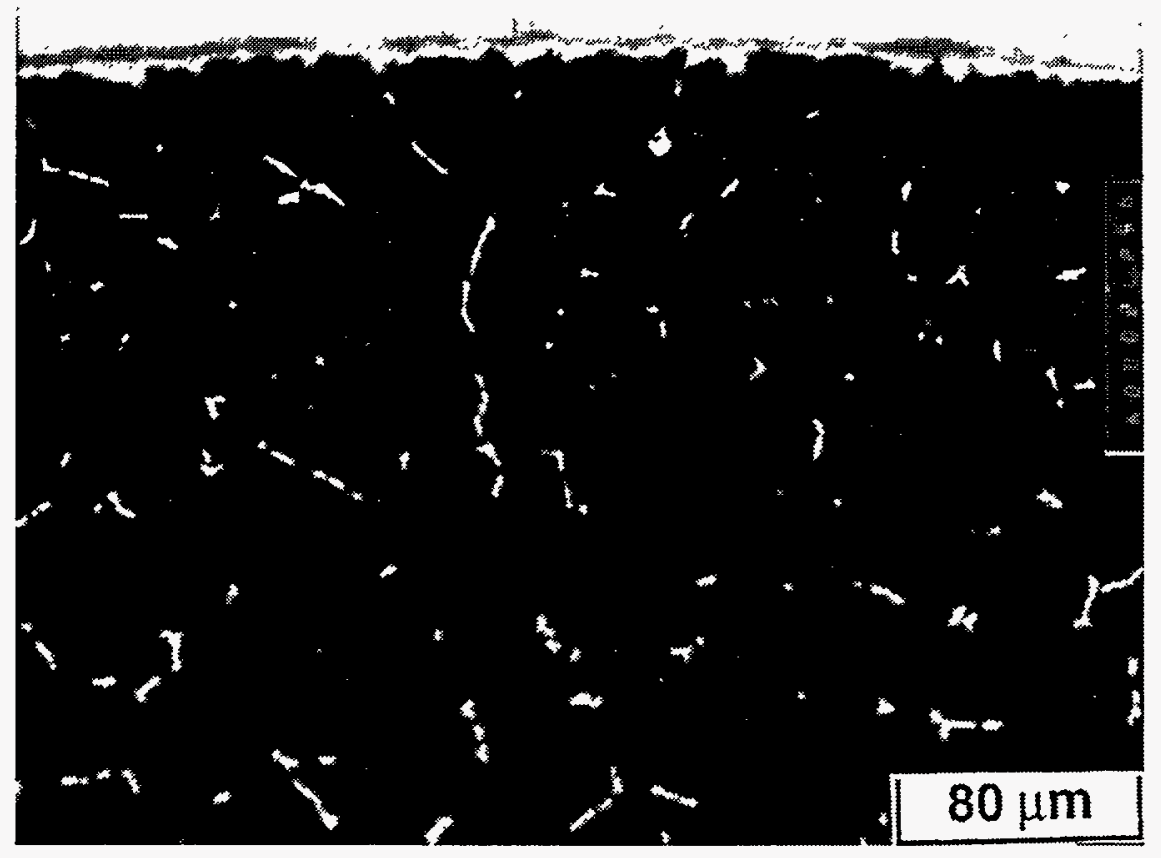

Figure 4.3. Reflective light photomicrograph of tantalum test specimen thermally processed for 25 hours at $1700^{\circ} \mathrm{C}$ in the absence of the packed-bed carbon media. The test specimen was thermally processed in a tantalum crucible absent of carbon during the carburization of the test specimen presented in Figure 4.2. A slight carbide coating and carbide precipitation can be observed. The carbide coating thickness measured to be 4 microns. 
The interactions between oxygen and tantalum and oxygen and carbon could significantly affect the results of the experimental campaign. Thus, a study of the chamber atmosphere was conducted to verify that no oxygen was present in the furnace during the carburization process. The discussion which follows is inserted only as a means to illustrate the concerns of conducting the carburizing process in the presence of oxygen. An in-depth study of the effects of the presence of oxygen would be rigorous and was out of the scope of this investigation.

In elevated temperature air atmospheres, tantalum reacts with oxygen to form a coating of $\mathrm{Ta}_{2} \mathrm{O}_{5}$ on the surface of the tantalum metal. The tantalum-oxygen reaction is substantial at much lower temperatures than those of the tantalum-carbon reactions. In addition, tantalum has a solubility for oxygen which is significantly greater than its solubility for carbon. At $1700^{\circ} \mathrm{C}$, tantalum has a solubility limit of 5.2 at.\% oxygen in tantalum, whereas its solubility limit for carbon is 0.7 at.\% carbon. It is not quit certain what the affects of dissolving or dissolved oxygen and the oxide coating on the tantalum substrate may have on carbide coating growth and dissolution kinetic of carbon. However, it is known that it is not possible to distinguish between oxide and carbide coatings and oxide and carbide precipitates via reflective light metallography.

Taking a look at a first approximation of the possible interactions of oxygen with tantalum and carbon and carbon with tantalum, the degree of complexity of the possible interaction is made obvious.

$$
\begin{aligned}
& \text { At } \mathrm{t}>0 \text { and } \mathrm{T}=298 \text { to } 1750^{\circ} \mathrm{K} \text {, } \\
& 5 \mathrm{Ta}+4 \mathrm{C}+4 \mathrm{O}_{2} \mathrm{TaO}_{2} \mathrm{O}_{5}+\mathrm{CO}_{2}+\mathrm{CO}+\mathrm{TaC}+\mathrm{TaC}_{2}
\end{aligned}
$$

As a first approximation, let us look at the individual reactions of each possible product which would form from the pure chemical elements independently.

$$
\begin{aligned}
& \text { At } t>0 \text { and } \mathrm{T}=298 \text { to } 1750^{\circ} \mathrm{K}, \\
& 2 \mathrm{Ta}+2.5 \mathrm{O}_{2} \mathrm{TaO}_{5} \\
& \mathrm{C}+\mathrm{O}_{2}^{2 \mathrm{CO}_{2}^{2}} \\
& \mathrm{C}+0.5 \mathrm{O}_{2}^{2} \mathrm{CO} \\
& \mathrm{Ta}+\mathrm{C} \mathrm{TaC} \\
& 2 \mathrm{Ta}+\mathrm{C} \mathrm{TaC}_{2}
\end{aligned}
$$

This first approximation only considers the interactions between the pure elements and does not consider interactions between product species. The Gibbs free energy of formation for 
each of the independent formation reactions have been plotted as a function of temperature in Figure 4.4. The plotted Gibbs free energies of formation have been normalized per atom oxygen and per atom carbon. The result that the Gibbs free energies of each product are negative indicates that these formation reactions are all possible. However, the analyses presented in the plot do not take into consideration the parameter of partial pressures of the interacting species. Thus, in the analysis the activities of the reacting species are assumed to be unity. This assumption is only valid for the reacting elemental species in the solid state. However, the activities of the gaseous species depend directly on their partial pressures.

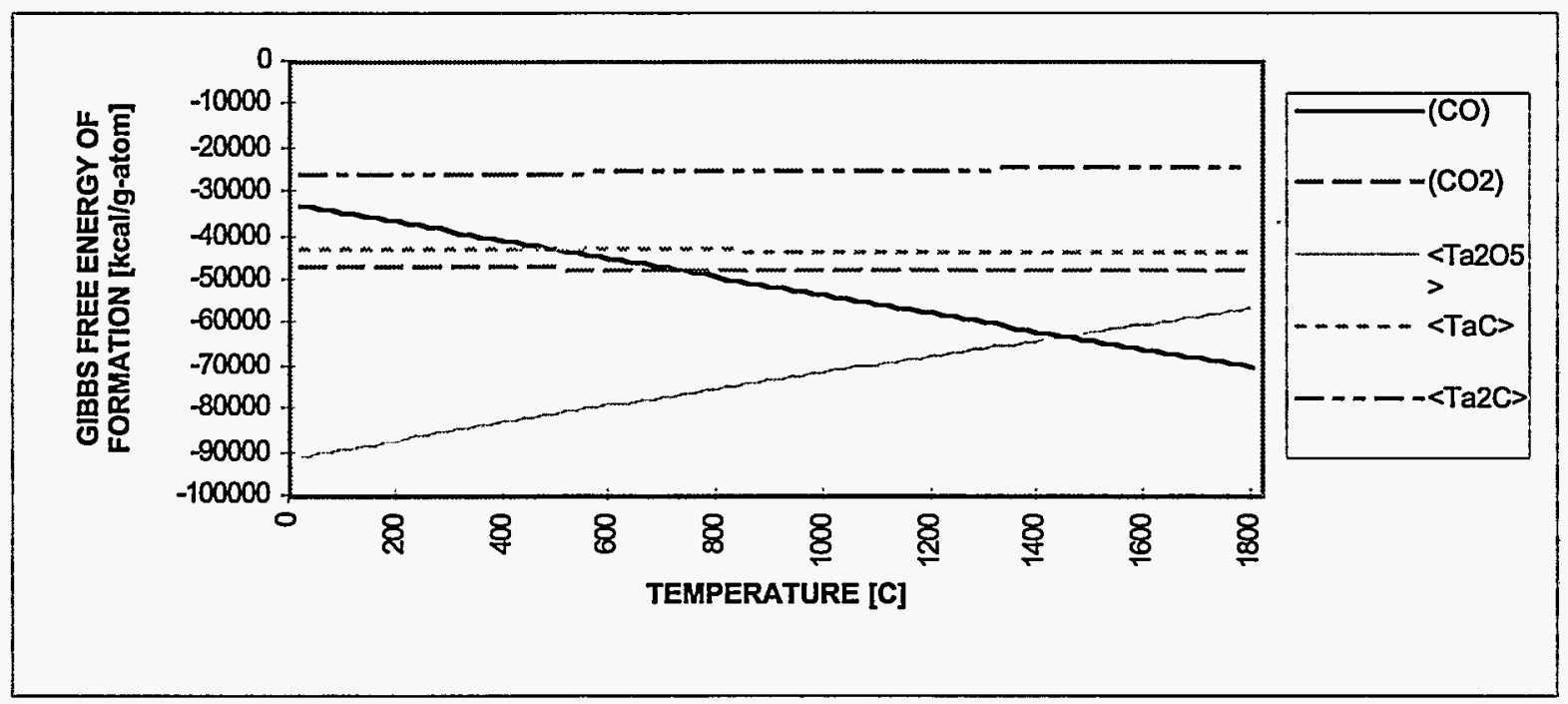

Figure 4.4. Gibbs free energies of formation for several elemental interactions. The free energies have been normalized per atom oxygen and carbon.

\subsection{Process Assessment}

A series of carburization runs were performed in order to establish a statistical baseline of carbide coating growth and weight gain during packed-bed carburization. Identical time and temperature parameters to be run in the bare versus presaturated study were followed. Including the test specimen carburized during the chamber atmosphere study, a total of four test specimens were carburized. Test specimens were carburized for 25 hours at $1700^{\circ} \mathrm{C}$.

To best compare results of measured coating thickness and weight gains observed for individual test specimens, a percent of theoretical value was calculated. By presenting the data as a percent of theoretical values, the author is also conveying information about the deficiencies 
in coating thicknesses. The percent of theoretical values calculated for coating thickness were calculated by dividing the measured thickness value of each specimen by the calculated theoretical coating thickness. Theoretical coating thickness values were calculated based on growth rate data reported by Krikorian. Percent of theoretical weight gain values were calculated by dividing measured weight gain values for each specimen by the theoretical weight gain. Theoretical weight gains were calculated by calculating the mole numbers of carbon associated with the volume of theoretical coating thickness on a specimen. Since weight gain is a function of the volume of coating, and the volume is determined by the thickness of coating on a surface area, the percent of theoretical values were normalized over the surface area available for carburization.

The mean percent of theoretical coating thickness was 71 percent and ranged from 67 to 73 percent of theoretical. Carbide coating thickness data is presented in Table 4.1. The percent of calculated results for coating thickness were much higher than anticipated. The mean percent of theoretical weight gains was 76 percent and ranged from 75 to 77 percent of theoretical. Weight gain data is presented in Table 4.2.

A summary of the percent of theoretical results for coating thickness and weight gain are presented in Table 4.3. The data presented reveals that the packed-bed carburization technique employed produced coatings of consistent repeatable thicknesses. The percent of theoretical weight gain for each specimen was, in every case, higher than the percent of theoretical coating thickness. Since theoretical weight gain is calculated based on theoretical coating thickness of carbide, the constantly higher percent of theoretical weight gain would tend to imply that the additional weight is due to carbon is solution.

The mole numbers of carbon soluble in the test specimens after 25 hours of carburization were calculated. The thickness of carbide coating $\left(\mathrm{TaC}+\mathrm{Ta}_{2} \mathrm{C}\right)$ that could be formed from the mole numbers of carbon soluble was calculated. The equivalent carbide coating thickness was summed with the observed coating thickness measured. The sum of the coating equivalent and the observed coating thickness summed to nearly 100 percent that of calculated theoretical carbide coating thickness. The results of this data appeared to further support the initial theory that the deficiencies observed in the coating thickness are due to simultaneous dissolution of carbon from the coating during carburization. The results of the summed values are presented in Table 4.4. 
Table 4.1. Observed and theoretical coating thicknesses for test specimens carburized in the process assessment phase of this investigation. The test specimens were carburized for 25 hours at $1700^{\circ} \mathrm{C}$. Theoretical coating thicknesses are calculated based on growth rate data reported by Krikorian.

\begin{tabular}{|c|c|c|c|}
\hline $\begin{array}{c}\text { Test } \\
\text { Specimen }\end{array}$ & $\begin{array}{c}\text { Observed } \\
\text { Coating } \\
\text { Thickness } \\
{[\mathrm{cm}]}\end{array}$ & $\begin{array}{c}\text { Theoretical } \\
\text { Coating } \\
\text { Thickness } \\
{[\mathrm{cm}]}\end{array}$ & $\begin{array}{c}\text { Observed/ } \\
\text { Theoretical }\end{array}$ \\
\hline \hline P1 & 0.0040 & 0.0060 & $67 \%$ \\
\hline P2 & 0.0043 & 0.0060 & $72 \%$ \\
\hline P3 & 0.0043 & 0.0060 & $72 \%$ \\
\hline AT1 & 0.0044 & 0.0060 & $73 \%$ \\
\hline \multicolumn{3}{|c|}{} & Mean 71\% \\
\hline \hline \multicolumn{3}{|c|}{ Test specimens carburized for 25 hours at 1700 } \\
\hline
\end{tabular}

Table 4.2. Observed and theoretical weight gains for test specimens carburized in the process assessment phase of this investigation. The test specimens were carburized for 25 hours at $1700^{\circ} \mathrm{C}$. Theoretical weight gains are calculated based on growth rate data reported by Krikorian.

\begin{tabular}{|c|c|c|c|}
\hline $\begin{array}{c}\text { Test } \\
\text { Specimen }\end{array}$ & $\begin{array}{c}\text { Observed } \\
\text { Weight } \\
\text { Gain } \\
\text { Normalized } \\
{\left[\mathrm{g} / \mathrm{cm}^{2}\right]}\end{array}$ & $\begin{array}{c}\text { Theoretical } \\
\text { Weight } \\
\text { Gain } \\
\text { Normalized } \\
{\left[\mathrm{g} / \mathrm{cm}^{2}\right]}\end{array}$ & $\begin{array}{c}\text { Observed/ } \\
\text { Theoretical }\end{array}$ \\
\hline \hline P1 & 0.0036 & 0.0048 & $75 \%$ \\
\hline P2 & 0.0036 & 0.0048 & $75 \%$ \\
\hline P3 & 0.0036 & 0.0048 & $75 \%$ \\
\hline AT1 & 0.0037 & 0.0048 & $77 \%$ \\
\hline \multicolumn{3}{|r|}{} & Mean $76 \%$ \\
\hline \hline \multicolumn{2}{|r|}{ Test specimens carburized for 25 hours at $1700^{\circ} \mathrm{C}$} \\
\hline
\end{tabular}


Table 4.3. Percent of theoretical data attained for coating thickness and weight gain during the process assessment phase of this investigation. All theoretical coating thicknesses and weight gains are calculated based on growth rate data reported by Krikorian. Test specimens were carburized for 25 hours at $1700^{\circ} \mathrm{C}$

\begin{tabular}{|c|c|c|}
\hline $\begin{array}{c}\text { Test } \\
\text { Specimen }\end{array}$ & $\begin{array}{c}\text { Observed/ } \\
\text { Theoretical } \\
\text { Coating } \\
\text { Thickness }\end{array}$ & $\begin{array}{c}\text { Observed/ } \\
\text { Theoretical } \\
\text { Weight } \\
\text { Gain }\end{array}$ \\
\hline \hline P1 & $67 \%$ & $75 \%$ \\
\hline P2 & $72 \%$ & $75 \%$ \\
\hline P3 & $72 \%$ & $75 \%$ \\
\hline AT1 & $73 \%$ & $77 \%$ \\
\hline \multicolumn{2}{|c|}{ Mean 71\% } & Mean $76 \%$ \\
\hline \hline Test specimens carburized for 25 hours at 1700 $\mathrm{C}$. \\
\hline
\end{tabular}

Table 4.4. The carbide coating thicknesses equivalent that could be formed from the mole numbers of carbon in solution were summed with the observed coating thicknesses measured. The sum was divide by the theoretical coating thicknesses calculated based on growth rate data reported by Krikorian to present a percent of theoretical value.

\begin{tabular}{|c|c|c|c|c|}
\hline $\begin{array}{c}\text { Test } \\
\text { Specimen }\end{array}$ & $\begin{array}{c}\text { Observed } \\
\text { Coating } \\
\text { Thickness } \\
\text { [cm] }\end{array}$ & $\begin{array}{c}\text { Theoretical } \\
\text { Coating } \\
\text { Thickness } \\
\text { Equivalent } \\
\text { of Carbon } \\
\text { in Solution } \\
\text { [cm] }\end{array}$ & $\begin{array}{l}\text { Sum } \\
{[\mathrm{cm}]}\end{array}$ & $\begin{array}{c}\text { Sum/ } \\
\text { Theoretical }\end{array}$ \\
\hline$\overline{\overline{\mathrm{P} 1}}$ & $\overline{0.0040}$ & $\overline{0.0016}$ & 0.0056 & $\overline{93 \%}$ \\
\hline$\overline{\mathrm{P} 2}$ & 0.0043 & 0.0016 & 0.0059 & $98 \%$ \\
\hline$\overline{\mathrm{P3}}$ & 0.0043 & 0.0016 & 0.0059 & $98 \%$ \\
\hline$\overline{\mathrm{AT} 1}$ & 0.0044 & 0.0016 & 0.0060 & $100 \%$ \\
\hline \multicolumn{5}{|c|}{ ized for 25 hours at 1700} \\
\hline
\end{tabular}




\subsection{Results of the Simultaneous Carburization of Bare and Presaturated Tantalum. Comparison Study}

A total of eight rods were carburized in the bare versus presaturated tantalum comparison study phase of this campaign. Three bare and three presaturated rods of the same nominal diameter, $0.291 \mathrm{~cm}$, and two larger diameter, $0.635 \mathrm{~cm}$, bare tantalum rods were carburized. Two carburization runs were performed. The first carburization run consisted of a $0.291 \mathrm{~cm}$ nominal diameter bare tantalum rod, a $0.291 \mathrm{~cm}$ nominal diameter presaturated tantalum rod, and a 0.635 $\mathrm{cm}$ nominal diameter bare tantalum rod. The second run consisted of two $0.291 \mathrm{~cm}$ nominal diameter bare tantalum rods, two $0.291 \mathrm{~cm}$ nominal diameter presaturated tantalum rods, and one $0.635 \mathrm{~cm}$ nominal diameter bare tantalum rod. A flowchart illustrating the process paths of specimens carburized in the chamber atmosphere study, the process assessment study, and the simultaneous carburization of bare and presaturated tantalum comparison study are presented in Figure 4.5.

Including the four specimens carburized in the process assessment study and the three specimens carburized in this study, a total of seven $0.291 \mathrm{~cm}$ nominal diameter rods were carburized. The mean percent of theoretical coating thickness of the seven specimens was 71 percent. The percent of theoretical thicknesses ranged from 67 to 73 percent.

A total of three presaturated test specimens were carburized. The mean percent of theoretical thicknesses was 66 percent. The percent of theoretical coating thicknesses ranged from 63 to 71 percent. The mean percent of theoretical coating thicknesses of the presaturated specimens was slightly less than the mean percent of theoretical coating thicknesses of bare tantalum specimens. Carbide coating thickness results of specimens carburized in bare versus the presaturated tantalum comparison study are presented in Table 4.5. Percent of theoretical coating thickness results of bare and presaturated specimens are summarized in Table 4.7.

The percent of theoretical weight gains of the bare $0.291 \mathrm{~cm}$ nominal diameter specimens were, in every case, greater than the percent of theoretical coating thickness. This trend was similarly observed in the process assessment study. The mean percent of theoretical weight gains for the seven smaller diameter bare tantalum specimens carburized was 76 percent. The percent of theoretical weight gains ranged from 75 to 77 percent.

The mean percent of weight gains for the three presaturated tantalum specimens carburized was 65 percent. The percent of weight gains ranged from 65 to 66 percent. Similar to the 
percent of coating thickness, the mean percent of theoretical weight gain for the presaturated specimens was less than that of the bare tantalum specimens.

The mean percent of theoretical weight gain was virtually the same as the mean percent of theoretical coating thickness for the presaturated specimens. This trend was anticipated and supports the assumption that there is no dissolution of coating into the carbon-saturated tantalum during carburization. The mean percent of theoretical weight gain was 65 percent. The mean percent of theoretical coating thickness was 66 percent. The weight gain results of specimens carburized in the bare versus presaturated tantalum comparison study are presented in Table 4.6. The percent of theoretical weight gain and coating thickness results of bare and presaturated specimens are summarized in Table 4.7.

The mean percent of theoretical coating thickness of the two $0.635 \mathrm{~cm}$ nominal diameter bare tantalum specimens was somewhat less than the mean percent of theoretical coating thickness of the seven smaller diameter bare specimens carburized. However, the mean percent of theoretical weight gain was the same as that of the smaller bare tantalum specimens carburized. This trend was anticipated. The mean percent of theoretical coating thickness was 63 percent. The mean percent of theoretical weight gain was 76 percent.

Table 4.5. Observed and theoretical coating thicknesses for test specimens carburized in the bare versus presaturated study. The test specimens were carburized for 25 hours at $1700^{\circ} \mathrm{C}$. Theoretical coating thicknesses are calculated based on growth rate data reported by Krikorian.

\begin{tabular}{|c|c|c|c|c|c|}
\hline & $\begin{array}{c}\text { Test } \\
\text { Specimen }\end{array}$ & $\begin{array}{l}\text { Initial } \\
\text { State }\end{array}$ & $\begin{array}{c}\text { Observed } \\
\text { Coating } \\
\text { Thickness } \\
\text { [cm] }\end{array}$ & $\begin{array}{c}\text { Theoretical } \\
\text { Coating } \\
\text { Thickness } \\
\text { [cm] }\end{array}$ & $\begin{array}{l}\text { Observed/ } \\
\text { Theoretical }\end{array}$ \\
\hline \multirow{3}{*}{ Run $1 *$} & $\overline{\mathrm{T1B}}$ & Bare & 0.0047 & $\overline{0.0065}$ & $\overline{72 \%}$ \\
\hline & T1S & C-sat. & 0.0046 & 0.0065 & $71 \%$ \\
\hline & T1BL** & Bare & 0.0041 & 0.0065 & $63 \%$ \\
\hline \multirow{5}{*}{ Run 2} & $\overline{\mathrm{T} 2 \mathrm{~B}-1}$ & Bare & 0.0042 & 0.0060 & $\overline{70 \%}$ \\
\hline & T2B-2 & Bare & 0.0041 & 0.0060 & $68 \%$ \\
\hline & T2S-1 & C-sat. & 0.0038 & 0.0060 & $63 \%$ \\
\hline & T2S-2 & C-sat. & 0.0038 & 0.0060 & $63 \%$ \\
\hline & T2BL** & Bare & 0.0037 & 0.0060 & $62 \%$ \\
\hline \multicolumn{6}{|c|}{ Test specimens carburized for 25 hours at $1700^{\circ} \mathrm{C}$. } \\
\hline $\begin{array}{l}* \mathrm{Ru} \\
* * 0.6\end{array}$ & . & & $\begin{array}{l}\mathrm{d} \text { for } 2 \\
\text { imen }\end{array}$ & at 1720 & \\
\hline
\end{tabular}




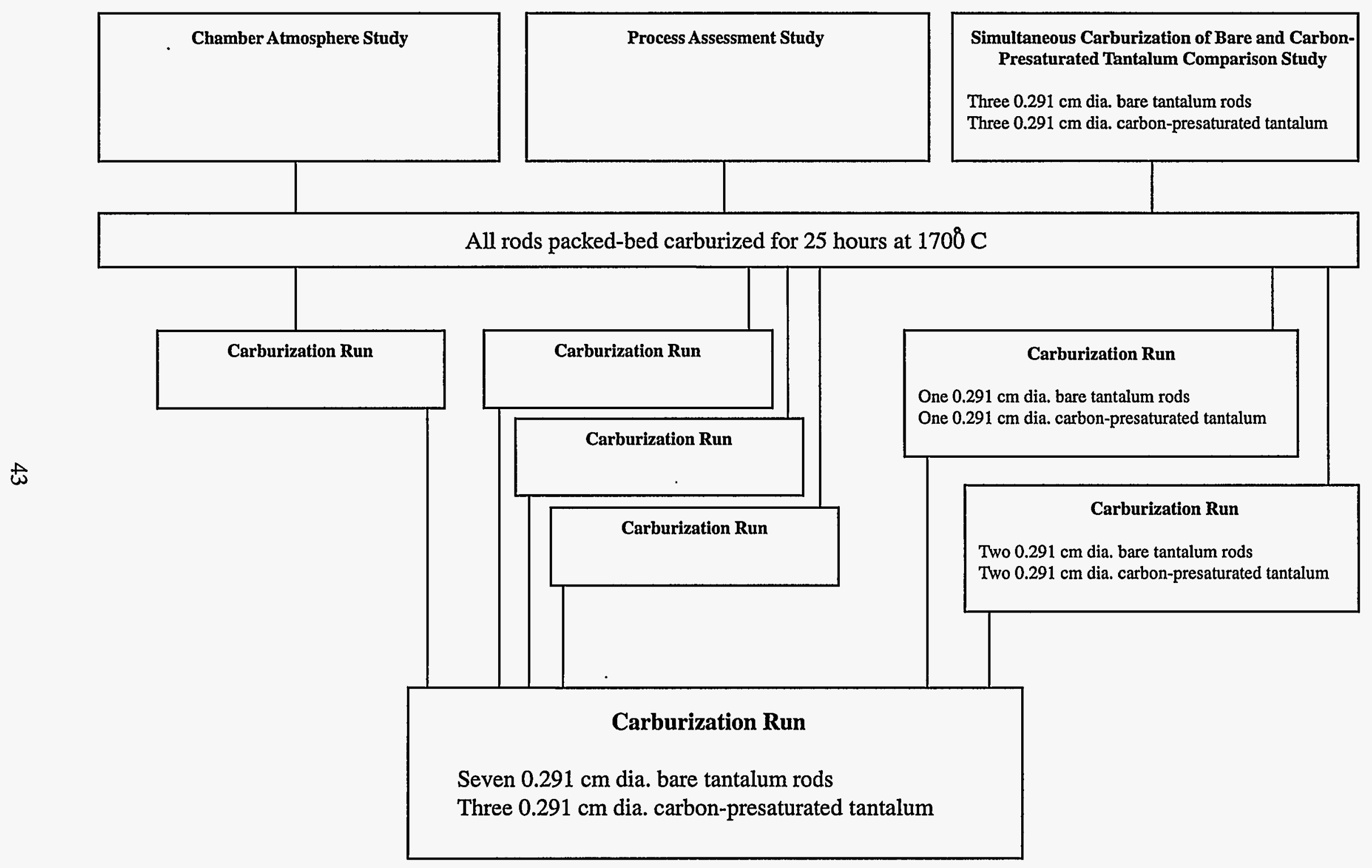

Figure 4.5 Flowchart of all test specimens carburized. 
Table 4.6. Observed and theoretical weight gains for test specimens carburized in the bare versus presaturated study. The test specimens were carburized for 25 hours at $1700^{\circ} \mathrm{C}$. Theoretical weight gains are calculated based on growth rate data reported by Krikorian.

\begin{tabular}{|c|c|c|c|c|c|}
\hline & $\begin{array}{c}\text { Test } \\
\text { Specimen }\end{array}$ & $\begin{array}{l}\text { Initial } \\
\text { State }\end{array}$ & $\begin{array}{c}\text { Observed } \\
\text { Weight } \\
\text { Gain } \\
\text { Normalize } \\
d \\
{\left[\mathrm{~g} / \mathrm{cm}^{2}\right]}\end{array}$ & $\begin{array}{l}\text { Theoretical } \\
\text { Weight } \\
\text { Gain } \\
\text { Normalized } \\
{\left[\mathrm{g} / \mathrm{cm}^{2}\right]}\end{array}$ & $\begin{array}{l}\text { Observed/ } \\
\text { Theoretical }\end{array}$ \\
\hline \multirow{3}{*}{ Run $1^{*}$} & T1B & $\overline{\text { Bare }}$ & $\overline{0.0041}$ & 0.0053 & $\overline{77 \%}$ \\
\hline & T1S & C-sat. & 0.0035 & 0.0053 & $66 \%$ \\
\hline & T1BL** & Bare & 0.0041 & 0.0053 & $77 \%$ \\
\hline \multirow{5}{*}{ Run 2} & $\overline{\mathrm{T} 2 \mathrm{~B}-1}$ & Bare & 0.0037 & 0.0048 & $77 \%$ \\
\hline & T2B-2 & Bare & 0.0036 & 0.0048 & $75 \%$ \\
\hline & $\mathrm{T} 2 \mathrm{~S}-1$ & C-sat. & 0.0031 & 0.0048 & $65 \%$ \\
\hline & T2S-2 & C-sat. & 0.0031 & 0.0048 & $65 \%$ \\
\hline & $\mathrm{T} 2 \mathrm{BL}^{* *}$ & Bare & 0.0036 & 0.0048 & $75 \%$ \\
\hline \multicolumn{6}{|c|}{ Test specimens carburized for 25 hours at $1700^{\circ} \mathrm{C}$. } \\
\hline
\end{tabular}


Table 4.7. Percent of theoretical coating thickness and weight gain data recorded for all test specimens carburized for 25 hours at $1700^{\circ} \mathrm{C}$ over the course of this investigation. Theoretical coating thicknesses and weight gains are calculated based on growth rate data reported by Krikorian.

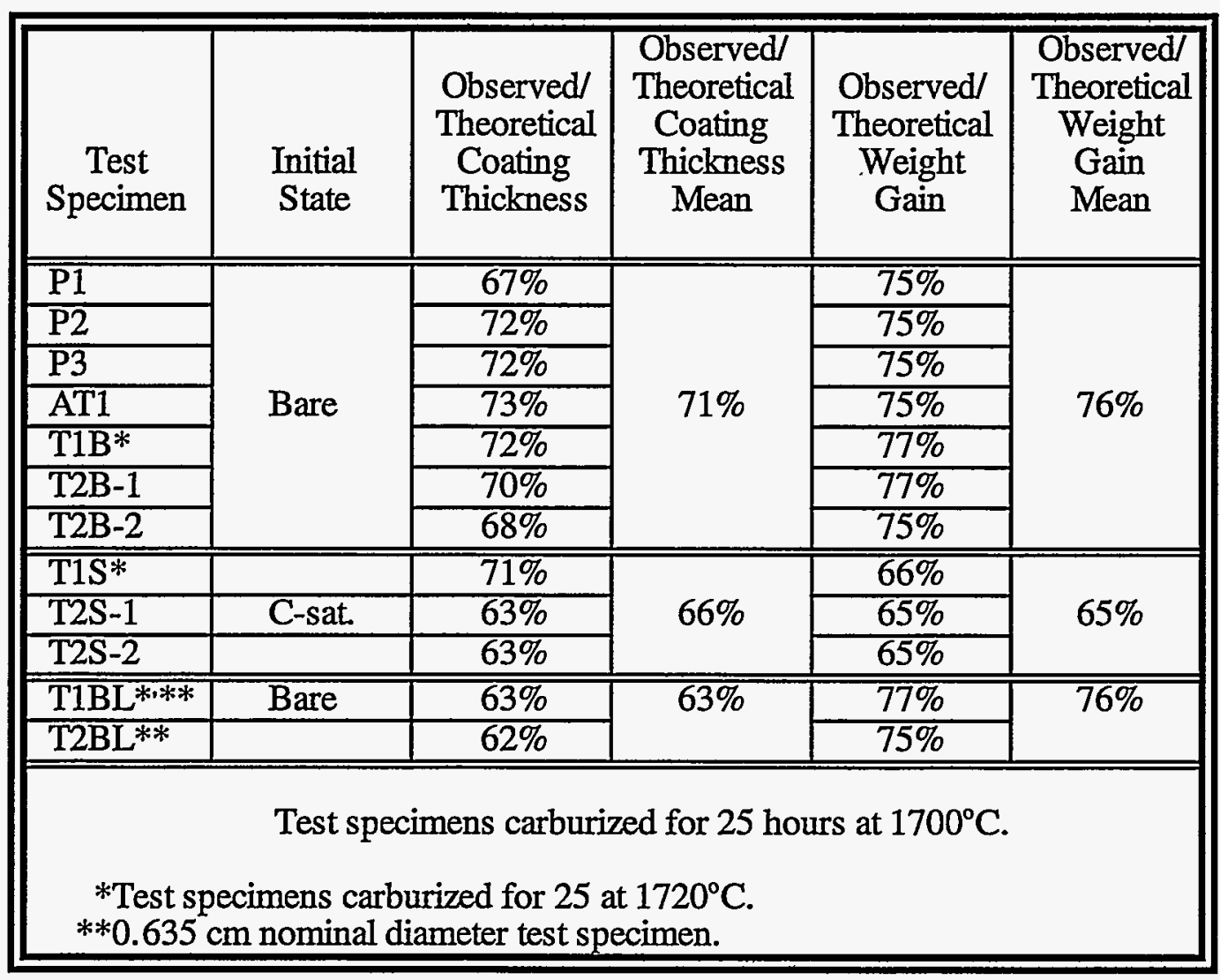




\subsubsection{Discussion of Results from the Simultaneous Carburization of Bare and Presaturated Tantalum Comparison Study}

At the inception of this investigation, a hypothesis was presented explaining the discrepancy between theoretical and observed carbide coating thicknesses: As the $\mathrm{TaC} / \mathrm{Ta}_{2} \mathrm{C}$ carbide coatings are formed, the coatings are depleted via decomposition of the carbide compounds and subsequent diffusion of nascent carbon into the tantalum substrate as the system moves towards equilibrium. It was theorized that it is this dissolution of the coating which is responsible for the observed deficiencies in carbide coating thicknesses. If this theory was to be proven true by this study, four trends were expected to be observed. The trends expected are outlined below in the form of four postulates:

(1) It was expected that the carbide coating thicknesses produced on the presaturated specimens would grow to that of theoretical thickness. This was expected because the presaturated test specimens were saturated with carbon from the onset of carburization. Therefore, dissolution of the coating (the competing reaction affecting net coating thickness) would not occur.

(2) It was expected that coating thickness achieved on the $0.291 \mathrm{~cm}$ nominal diameter bare tantalum rods would be greater than the coating thickness achieved on the 0.635 nominal diameter bare tantalum rods. This was expected because it would take 76 hours to saturate the larger diameter rods and only 16 hours to saturate the smaller diameter rods. In the latter case, a saturated condition could be reached over the time of carburization processing. Thus, during the 25 hours of carburization, carbide formation without the effects of dissolution of carbon from the coating could occur for 9 hours on the smaller diameter rods. Based on the larger mass of the tantalum provided in the larger specimens, equilibrium solubility would not be achieved over the time of carburization. Thus, dissolution of carbon from the coating would continue over the complete time of carburization.

(3) It was expected that the percent of theoretical weight gains would be greater than the percent of theoretical coating thicknesses for the bare tantalum rods carburized. This was expected because it was theorized that carbon deficit in the coatings would be accounted for as carbon in solution. A mass balance could be generated by calculating the carbon weight contributions from the coating and from dissolved carbon (technically precipitates at ambient temperature). 
(4) It was expected that the percent of theoretical weight gains would agree with the percent of theoretical coating thicknesses for the presaturated rods carburized. This was expected because, since no increase in carbon would be accommodated into the tantalum matrix during carburization, the only weight gain should be due to carbon gained in the form of carbide coating.

Results of the experimental campaign provided insight into the mechanisms influential in coating production and disproved the hypothesis put forth. The dissolution effects of forming the tantalum-carbon solid solution have been illustrated as inconsequential in the production of coating thicknesses over the time regime of industrial interest. Based on the data collected, a response to the trends expected in the experimental campaign follows:

(1) Contrary to what was expected, the carbide coating thicknesses achieved on the presaturated specimens did not grow to that of theoretical thicknesses. The mean percent of theoretical coating thicknesses achieved on the presaturated specimens was similar but slightly less than that achieved on the bare tantalum rods of similar diameter.

(2) As expected, the mean carbide coating thicknesses achieved on the smaller diameter bare tantalum specimens was greater than the mean coating thicknesses achieved on the larger diameter bare tantalum specimens.

(3) As expected, the mean percent of theoretical weight gains was greater than the mean percent of theoretical coating thicknesses for the bare tantalum rods carburized.

(4) As expected, the mean percent of theoretical weight gains corresponded to the mean percent of theoretical coating thicknesses of the presaturated tantalum rods carburized.

The trend observed in the data pertaining to postulates (1) and (4) shows that the dissolution of carbon from carbide coating during carburization is not the rate limiting factor in the formation rates of the coating growth. If the dissolution was the rate limiting factor, the coating thicknesses on the presaturated specimens would have grown to theoretical thicknesses. Thus, contrary to the theory proposed, the dissolution of carbon from the carbide coating during carburization is not responsible for the coating thickness deficiencies observed. The trends observed in the data pertaining to postulates (2) and (3) support the observation that there is concurrent dissolution of carbon from the carbide coatings during carburization. Dissolution of carbon during carburization was also confirmed metallographically. Carbide precipitates decoration of 
the tantalum matrix was always observed in all carburized samples viewed metallographically.

Having determined that dissolution of carbon from the carbide coating during carburization is not the rate limiting factor in the coating formation rate, the author would like to offer a few possible alternative explanations that could help explain the coating thickness deficiencies observed. The temperature dependent growth rate constants reported by Krikorian ${ }^{29}$ were determined by plotting and curve fitting rate constant data versus the inverse of carburization temperature. The data which Krikorian used to calculated growth rate constants for $\mathrm{TaC}$ and $\mathrm{Ta}_{2} \mathrm{C}$ growth was extracted from a collection of measured carbide coating thicknesses. The collection of measurement data was a combination of data from Krikorian's own work and four other published investigations. The coating thicknesses were measured off test specimens which were carburized for 10 hours or less. A majority of those carburization runs were 2 hours or less. During the current experimental campaign, test specimens were carburized for 25 hours. Thus, it is possible that the growth rate constants reported by Krikorian are not accurate for longer carburization times.

Another possible factor influencing the observed deficiencies in coating thicknesses may be due to carbide coating thickness measurement inconsistencies and inaccuracy. Krikorian determined the growth rate constants based on a collection of measured thicknesses of prepared coatings. The coatings were prepared and measured by four different investigators. It is possible that inconsistencies and inaccuracies associated with the measurement of coating thicknesses (previously documented in this work) could incur a relatively large error associated with the growth rate constants. It is possible that the carbide coating deficiencies observed may fall within this error. However, the statistics associated with measured coating thicknesses were not addressed by Krikorian, nor the investigators from which Krikorian used data. The digital imaging measurement technique developed in this experimental campaign reduces error associated with precision carbide coating thickness measurement, which directly reduces error associated with the growth rate constants.

The possibility that carbide coating growth on the presaturated test specimens carburized in this study may have been influenced by some other facts which caused the coating thickness on the presaturated specimens to be deficient was considered. One consideration was the fact the presaturated specimens were carburized via gas phase carburization. It was surmised that during gas phase carburization, nascent hydrogen from decomposed methane could be dissolved into the matrix of the specimens. During the work ${ }^{3}$ in which the carbon-saturated specimens were prepared, this issue was evaluated and rejected. 
Tantalum does possess a substantial solubility for hydrogen. However, the tantalumhydrogen system exhibits retrograde solubility over the temperatures of interest. Tantalum possesses virtually no solubility for hydrogen at the processing temperature Axler employed. Also, in that work by Axler, the carbon-saturate specimens were analyzed for composition by electron probe microanalysis and chemical analysis. No evidence of the presence of dissolved hydrogen was reported. Thus, the author believes that it is not possible that dissolved hydrogen in the presaturated specimens could have influenced the carbide growth thicknesses of the presaturated specimens carburized in the current study.

Another possible explanation which was considered was the possibility that formation growth rate constants are specific to the carburizing method. This would imply that the kinetics of the formation reaction is the rate limiting factor and that the formation reaction rates are different for different carburization methods. Thus, the formation reaction rate for packed-bed carburization, packed-bed carburization in a hydrogen atmosphere, and each gas phase carburization method employing a different hydrocarbon gas would be different. This possibility is plausible, but Krikorian used a collection of coating thickness data to calculating the growth rate constants. The data was collected from investigators who used packed-bed carburization, packed-bed carburization in a hydrogen atmosphere, and gas phase carburization in a methane/ argon atmosphere to produce carbide coatings. The growth rate constants reported by Krikorian should be an average of the different formation reaction rates, if any existed. Thus, the effects of having different formation reaction rates should have been minimized using the combined data to determine the growth rate constants.

Vaporization or de-carburization of the coatings is another possible explanation considered which could explain the carbide coating thickness deficiencies observed. The vaporization of the carbide coatings has been investigated by Wallace and Butt. ${ }^{51}$ Based on vaporization behavior of the carbides, it was determined that no significant loss of the coating could be expected.

The loss of coating thickness due to de-carburization could have been possible. De-carburization involves reacting the carbide coating with oxygen to form $\mathrm{CO}$ and $\mathrm{CO}_{2}$. Thus, the presence of oxygen during carburization would be required. Precautions were taken to eliminate any oxygen from the furnace chamber. Before temperature was applied in the furnace, the furnace chamber was evacuated of oxygen by employing a multistep argon purge and evacuation process. The high-temperature carburization was conducted with the furnace chamber under vacuum. In addition, a test of the furnace chamber atmosphere was conducted during this 
investigation. Based on the chamber atmosphere test conducted and the precautions taken to ensure a minimal presence of oxygen in the chamber during carburization, it was determined that no significant partial pressure of oxygen was present during carburization. Thus, the possibility of de-carburization contributing to the observed coating thickness deficiencies was discounted.

\subsection{Discussion of the Applications of Carbon-Saturated Tantalum}

Carbon-saturated tantalum was designed for applications in various severe pyrochemical and pyrometallurgical plutonium processing processes. Carbon-saturated tantalum hardware could improve hardware longevity, reduce personnel exposure to radiation, and reduce nuclear waste generation.

Hardware employed in pyrochemical and pyrometallurgical plutonium processing are exposed to extremely severe environments. In general, the most severe environments identified involve exposing hardware to pure chlorine gas and to molten $\mathrm{PuO}_{2}, \mathrm{CaO}, \mathrm{CaCl}_{2}, \mathrm{KCl}, \mathrm{NaCl}$, calcium metal, and plutonium metal—all at elevated temperatures.

Knowledge gained during the course of this investigation was used to carbon-saturate tantalum hardware to be tested in an experimental plutonium recovery method. The method involves exposing the experimental carbon-saturated test crucible to hydrogen gas and liquid plutonium at elevated temperatures.

Carbide coating growth rate knowledge about packed-bed carburization gained during the course of the current investigation was applied to calculate optimum carburization and annealing times. The experimental crucible was carburized for 10 hours at $1700^{\circ} \mathrm{C}$. The crucible was annealed under vacuum at $1600^{\circ} \mathrm{C}$ for 35 hours. Metallography was performed on witness material section out of the crucible in the as received condition, after carburization, and after annealing.

A reflective light photomicrograph illustrating the grain structure of the test crucible tantalum in the as-received condition is presented in Figure 4.6. A reflective light photomicrograph illustrating the crucible tantalum after carburization is presented in Figure 4.7. The lower region is the tantalum matrix. Slight carbide decoration of the grain boundaries can be observed. The two distinct white layers are the $\mathrm{TaC}$ and $\mathrm{Ta}_{2} \mathrm{C}$ coating. The uppermost phase is $\mathrm{TaC}$, and the $\mathrm{Ta}_{2} \mathrm{C}$ phase lies between the $\mathrm{TaC}$ phase and the metal substrate. The carburization produced a carbide coating 25 microns thick on the crucible. 
Reflective light photomicrograph illustrating the test crucible tantalum after the annealing process is presented in Figure 4.8. It is observed that full carbide decoration of the grain boundaries was achieved. In a comparison of the substrate grain size of the as-received condition (Figure 4.6) and the annealed condition, it is evident that significant grain growth occurred. The increase in grain size is evidence that the formation of precipitates occurred during cooling. Otherwise, if grain boundary precipitates had formed during carburization soak time or annealing soak time, the grains would not have grown nearly as much due to grain boundary pinning by the precipitates.

It is revealed in Figure 4.8 that the entire carbide coating was not completely dissolved. The remaining coating phase was determined to be $\mathrm{Ta}_{2} \mathrm{C}$. It is known that the phase is $\mathrm{Ta}_{2} \mathrm{C}$ because after the annealing process the crucible was no longer the typical $\mathrm{TaC}$ gold color. Instead, the crucible was the metallic gray color typical of $\mathrm{Ta}_{2} \mathrm{C}$.

In a past study, ${ }^{3}$ it was found that coated carbon-saturated tantalum is inferior to the carbon-saturated alloy absent of a carbide coating. This is true due to the wetting behavior of the carbides. Thus, the excess coating presented a problem and required removal. The removal of the carbides is nontrivial due to their substantial hardnesses. The Knoop hardness of the $\mathrm{Ta}_{2} \mathrm{C}$ phase has been reported ${ }^{14}$ to be as high as $9.8 \mathrm{GPa}$. In addition, tantalum metal is difficult to machine, and the shapes of many crucibles do not lend themselves to traditional machining practices.

In the course of reviewing background literature on the tantalum-carbon system, a single sentence in a work by E. K. Storms ${ }^{42}$ was encountered concerning the chemical stability of TaC. The reference stated that $\mathrm{TaC}$ is very stable towards acids but will dissolve in a mixture of $\mathrm{HNO}_{3}$ and HF.

This information was discussed with Ramiro Pereyra, a Los Alamos metallography expert. From this discussion and some slight experimentation, Pereyra arrived at an acid wash solution of $1 / 4 \mathrm{HNO}_{3}+1 / 4 \mathrm{HF}+1 / 2$ lactic acid.

The acid wash was applied continuously to the crucible for 15 minutes. The crucible was then rinsed in water. Reflective light photomicrographs of the results of the acid are presented in Figure 4.9. It can be observed that the acid wash sucessfully removed the $\mathrm{Ta}_{2} \mathrm{C}$ coating. Take particular note in Figure 4.9 that the acid wash did not attack $\mathrm{Ta}_{2} \mathrm{C}$ inclusions at the grain boundaries. This is of significant importance because the $\mathrm{Ta}_{2} \mathrm{C}$ inclusions at the grain boundaries is the primary corrosion inhibiting mechanism. 

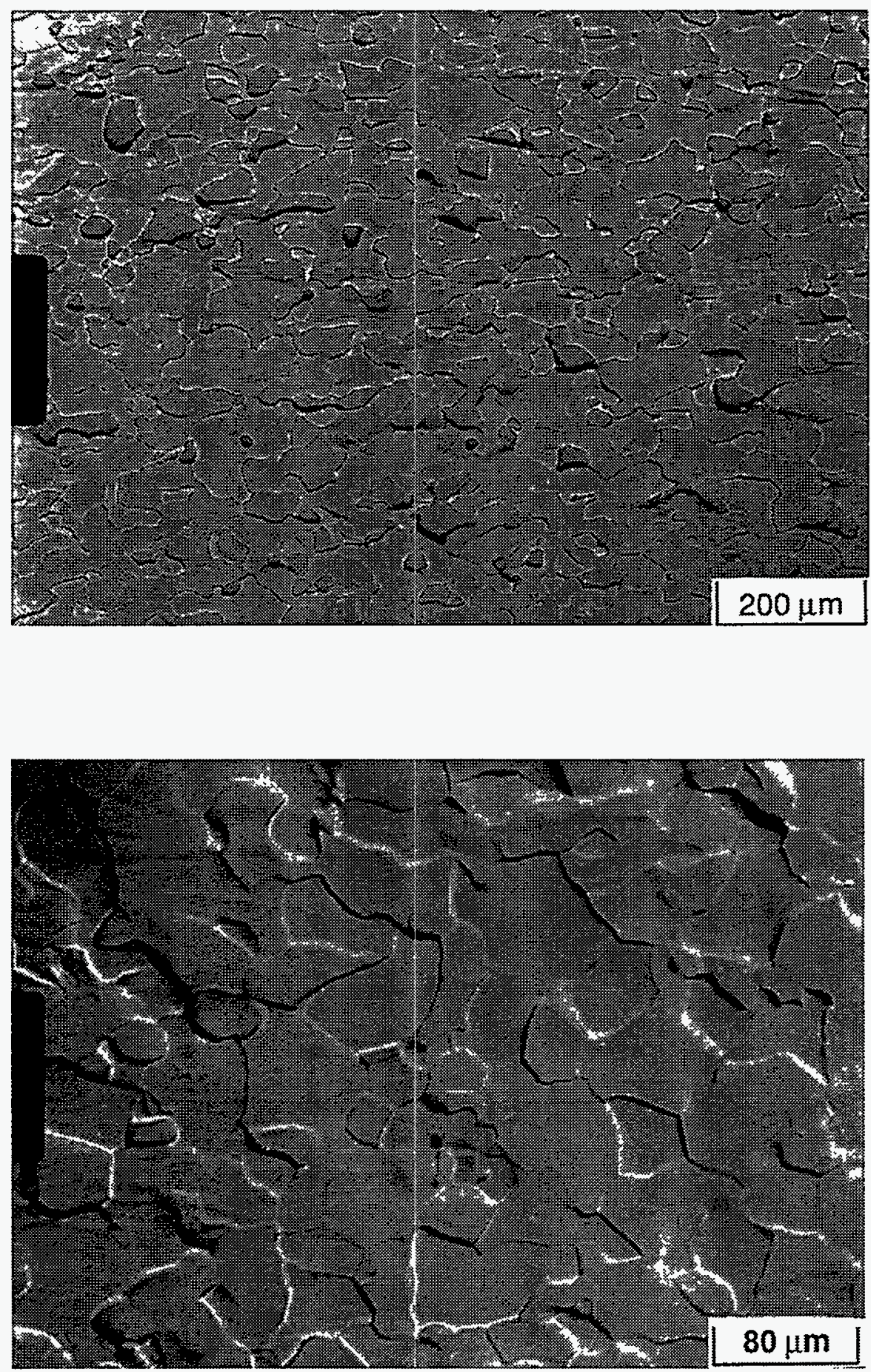

Figure 4.6. Reflective light photomicrographs of test crucible tantalum in the as-received bare condition. 

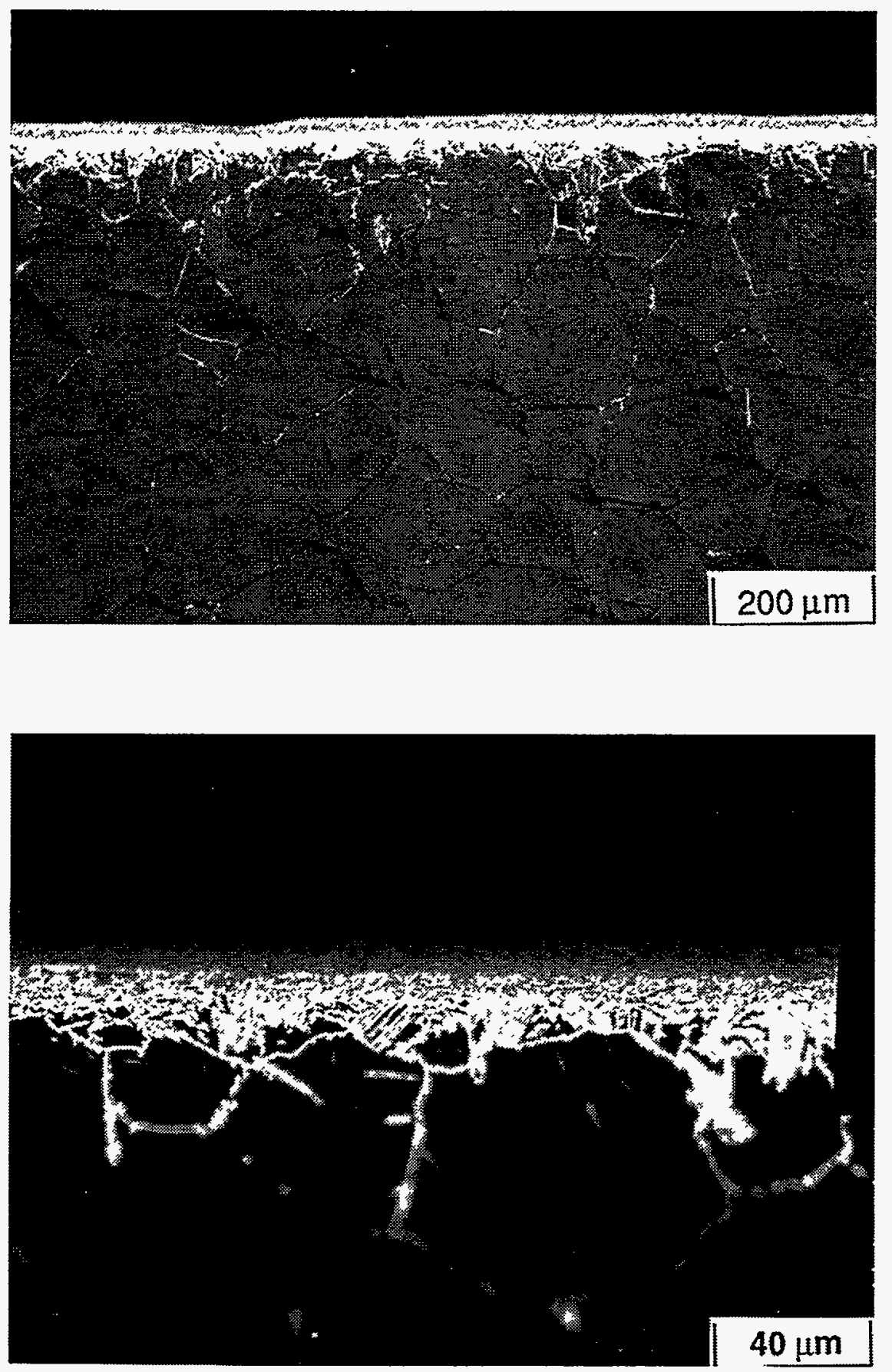

Figure 4.7. 1Reflective light photomicrographs illustrating the test crucible tantalum after carburization. The lower region is the tantalum matrix. Slight carbide decoration of the grain boundaries can be observed. The two distinct white layers phases are the $\mathrm{TaC}$ and $\mathrm{Ta}_{2} \mathrm{C}$ coating. The uppermost phase is $\mathrm{TaC}$. The $\mathrm{Ta}_{2} \mathrm{C}$ phase lies between the $\mathrm{TaC}$ phase and the metal substrate. The crucible was carburized at $1700^{\circ} \mathrm{C}$ for 10 hours. The crucible carburization produced a carbide coating 25 microns thick. 

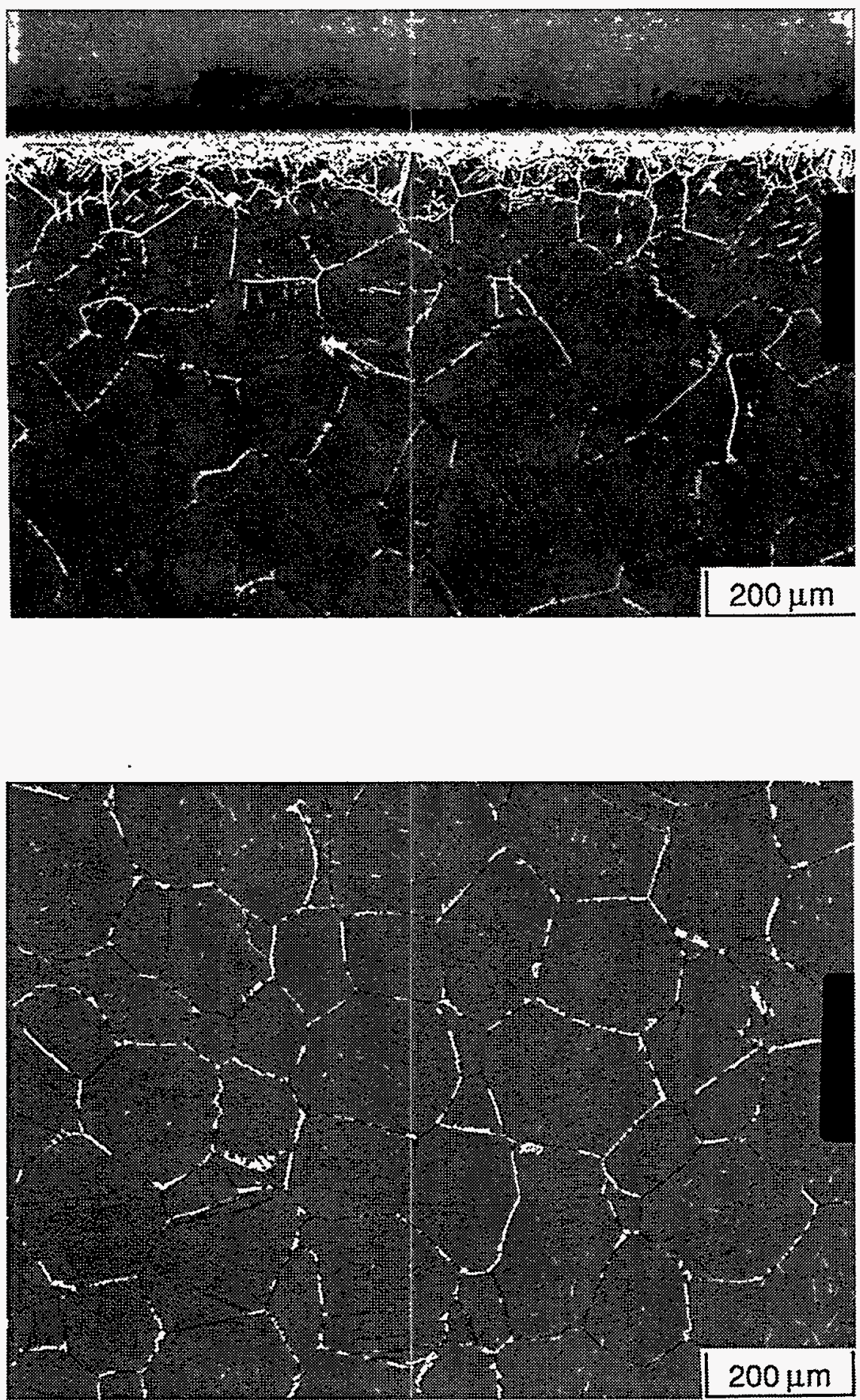

Figure 4.8. Reflective light photomicrographs illustrating the test crucible tantalum after the annealing process. It can be observed that full carbide decoration of the grain boundaries was achieved. In the first photomicrograph above, it is revealed that the entire carbide coating was not completely dissolved. The remaining coating phase was determined to be $\mathrm{Ta}_{2} \mathrm{C}$. 

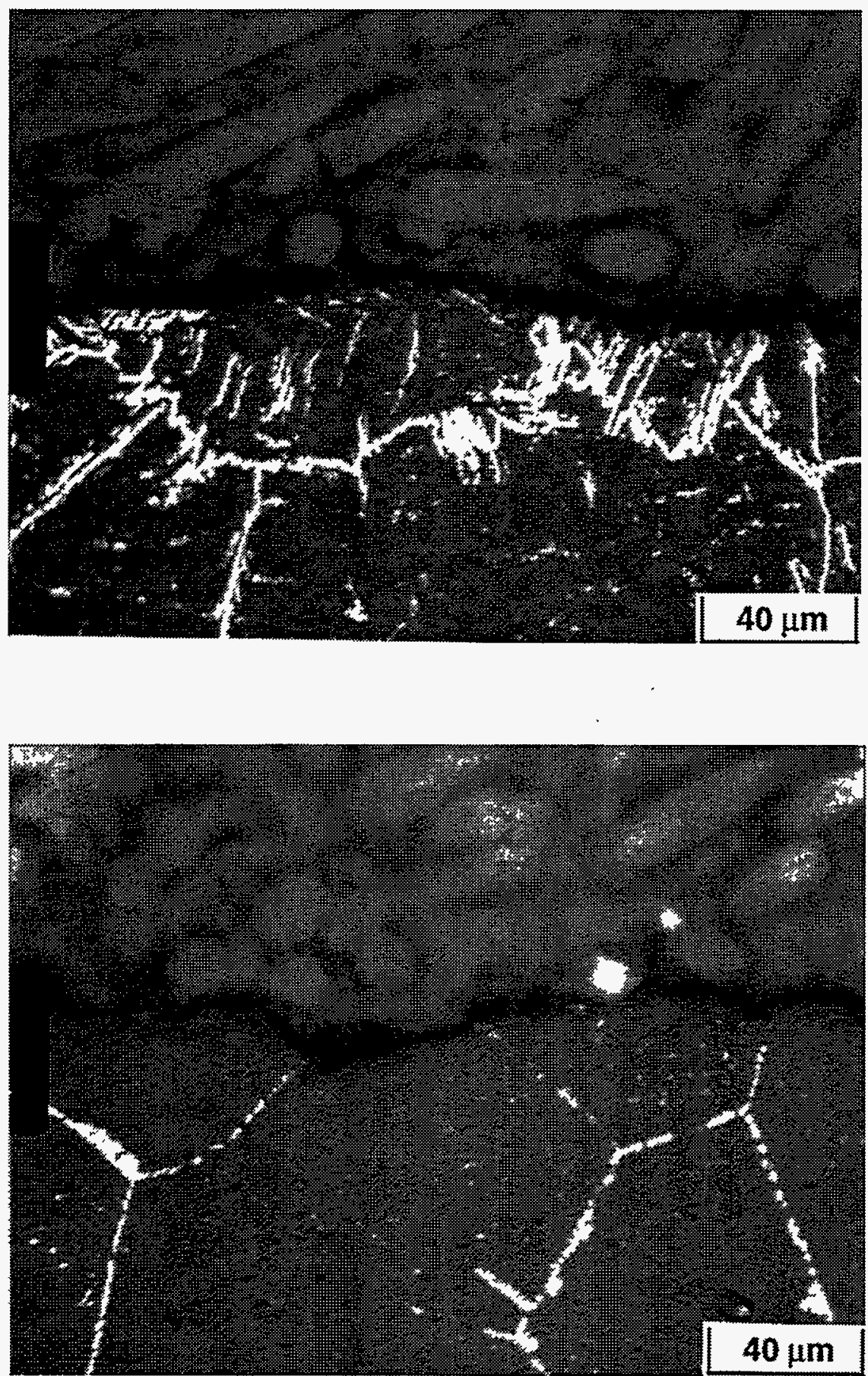

Figure 4.9. Reflective light photomicrographs illustrating the results of the acid wash procedure. It can be observed that the acid wash procedure was successful in removing the $\mathrm{Ta}_{2} \mathrm{C}$ coating. Take particular note that the acid did not attack $\mathrm{Ta}_{2} \mathrm{C}$ inclusions at the grain boundaries. 


\subsection{Summary and Conclusions}

This investigation was successful in applying materials research to optimize an engineering application. The interactions between carbide coating formation rates and dissolution kinetics in the tantalum-carbon system were investigated. The research was driven by the need to characterize carbide coating formation rates so that an optimum processing scheme for the fabrication of carbon-saturated tantalum hardware could be engineered.

New insight on the complexity of carbide coating growth kinetics was gained and described in this work. The experimental campaign was successful in elucidating information about the observed deficiencies in carbide coating thickness. Contrary to what was expected, it was found that although there is dissolution of carbon from the carbide coating during the carburization process, the dissolution of the carbon from the carbide coating is not the rate limiting factor of the coating formation rates. Thus, the dissolution of carbon from the carbide coating during carburization is not the responsible factor for the coating thickness deficiencies observed.

The overall investigation was successful in the engineering of a carburizing scheme which produced consistent, repeatable, and predictable carbide coatings. The packed-bed carburization scheme employed consistently produced coating thicknesses that were closer to theoretical than those observed in earlier investigations at Los Alamos National Laboratory in which gas . phase carburization was employed. During the course of this investigation, fabrication of fullscale, carbon-saturated hardware to be employed in severe environments was demonstrated.

\subsection{Further Accomplishments}

Over the course of this investigation, several ancillary applications significant to tantalum-carbide coating applications were developed. An acid wash for the removal of excess carbide coatings on the surface of carbon-saturated hardware was developed. The acid was successfully demonstrated to remove excess surface carbide coatings without affecting the corrosion inhibiting microstructure of carbon-saturated tantalum. A novel digital imaging carbide coating measurement technique was developed. The digital imaging measurement technique employs Adobe Photoshop's gray scale discriminator function to distinguish and measure the carbide coating in a selected area. The digital imaging analysis method alleviates the tedious nature and uncertainties associated with measuring carbide coating thickness. 


\subsection{Further Investigations}

The surface of possible investigations related to the corrosion resistant carbon-saturated tantalum composite has only been scratched. Further investigations could involve characterizing growth rates of tantalum carbide coatings via packed-bed carburization. The investigation could employ higher carburization temperatures and shorter carburization times. The mechanical properties of carbon-saturated tantalum composites could be investigated for improved machinability of tantalum. Carbon-saturated composite development and corrosion resistance studies of systems similar to the tantalum-carbon system could be investigated. Niobium, niobium-tantalum, and tantalum-tungsten alloys are possible candidates.

Niobium-tantalum alloys are particularly attractive because the niobium-carbon system is remarkably analagous to the tantalum-carbon system. Although niobium is less corrosion resistant than tantalum, niobium has a density of nearly one-half that of tantalum and the analagous $\mathrm{NbC}$ and $\mathrm{Nb}_{2} \mathrm{C}$ intermediates posses substantial formation rates at temperatures significantly lower that those of the tantalum carbides. In addition, carbon dissolution is formidable at significantly lower temperatures.

\subsection{Appendix A}

\subsection{Digital Imaging Analysis For Carbide Layer Measurement:}

The following discussion is a detailed step-by-step account of digital optical analysis for the carbide coating layer measurement procedure developed in the course of this study. To my knowledge, this is a new and unique measurement method. I have included this detailed appendix because it is my hope that this method may benefit future investigators. It is my belief that this measurement procedure improves carbide layer measurement accuracy and constancy, and alleviates some of the tedious work associated with measuring surface carbide thickness. The discussion which follows is a chronological description of the measurement procedure followed in the analysis.

\section{Equipment Used:}

(1) Leco 300 optical metallograph

(2) 4.2 Mega-Plus Kodak digital camera

(3) 4.2 Mega-Plus Kodak digital camera controller (camera computer interface)

(4) Macintosh Quadra 950 computer 
(5) NIH Image 1.55 software

(6) Adobe Photoshop 2.5 software

Step-By-Step Procedures:

(1) The carburized tantalum rod specimens were cross-sectioned normal to the length. The cross-sectioned specimens were metallographically prepared by a polishing and etching procedure developed specifically for tantalum-carbon alloys by Pereyera. ${ }^{50}$ The etching process uses potassium-hydroxide in place of the conventional etchants (hydrofluoric acid, nitric acid, and lactate acid) generally used on tantalum alloys. The use of the alternative etchant increases contrast in color between the carbides and the tantalum metal when observed optically.

(2) The specimens were loaded into the Leco 300 metallograph. The area of interest on a specimen was focused in on. The light and color filters were adjusted such that the greatest contrast in color between the carbide and tantalum was obtained. The green color filter provided the best results.

(3) NIH Image 1.55 software was used to capture images digitally. The best measurement results were achieved when the metallograph provided a 500 times magnification. The digital camera induced a 4.1 times magnification. Thus, when the images appear on the computer monitor at a 1-to-1 scale, the images are a 2050 times magnification. To commence the capturing sequence, the "Start Capturing" command from the "Special" menu was initiated. The images were once again focused, and the light intensity was adjusted on the metallograph. It was sometimes necessary to adjust the gain on the camera controller in order to capture the images as desired. The intent was to obtain a combination of light and gain intensity such that the $\mathrm{TaC}$ and $\mathrm{Ta} C$ coatings appeared on the computer monitor as one white band. The images were captured such that the carbide coatings appeared either horizontal or vertical on the monitor (see Figure 3.4). When capturing, make sure that the software is set-up to capture gray scale images.

(4) The "Stop Capturing" command was initiated to stop the capturing process. The capturing process works like a digital movie. A series of frames are taken until the capturing is stopped. Only the final frame was saved.

(5) The images were then saved so that analysis could be performed using Adobe Photoshop. Four images were captured from each specimen. Multiple images were used so that an average carbide coating thickness could be calculated. 
(6) The NIH Image files were opened from Adobe Photoshop. Make sure that the software is set-up to receive gray scale images.

(7) Upon opening the file, the scale of the image generally was not a 1-to-1 scale. Thus, the image scale was set to 1-to-1 with the "Zoom" command from the "View" menu.

(8) The image was sharpened using the "Sharpen" command from the "Filter" menu.

(9) An exact rectangular area for the "Marquee" tool from the "Tool" bar was set. The "Marquee" tool area width and height were generally set to $400 \times 600$ pixels or vise versa depending on the orientation of the coating in the image.

(10) The "Marquee" tool was used to select a region of the coating to be measured. The rectangular area was selected such that the coating length was parallel to the rectangular length (see Figure 3.4).

(11) The "Threshold" command within the "Map" command from the "Image" menu was initiated. The threshold level was adjusted, when necessary, to increase or decrease the threshold distinction between white and black. Sometimes it was necessary to use the "Paint Brush" tool from the "Tool" bar to correctly color areas which were misinterpreted.

(12) To review the threshold analysis, the "Histogram" command from the "Image" menu was initiated. The histogram command provided analysis of total pixel white and black with the marquee selected area. To determine the total area white (carbide) within the marquee selected area, the cross hair was placed at the 100 percentile white. The total pixels white was recorded and used in the carbide thickness measurement calculations.

(13) Knowing the number of white pixels (carbide) in the selected area, it is possible to calculate the average carbide thickness within the analyzed area. Using the known length mapped and the area of carbide within the analyzed section, the equation for the area of a rectangle was used to calculate a normalized carbide layer width in pixels. Knowing the number of pixels in a unit length and the magnification of the optical image, the width in pixels was converted to length in microns. Four measurements per specimen were taken to determine an average carbide layer thickness on the specimen. In order to demonstrate the calculations performed, I have presented a typical calculation for one measurement below: 


\section{Given:}

White pixels in analyzed area

166,266 pixels $^{2}$

Marquee rectangular area analyzed

$400 \times 600$ pixels

Pixels per inch

72 pixels/inch

Magnification

2050 times

Find: Calculate carbide coating thickness (width) in centimeters.

\section{Solution:}

- Area of carbide within analyzed area: $A=W * H$

- $\mathrm{A}$ and $\mathrm{H}$ are known, thus $\mathrm{W}=\mathrm{A} / \mathrm{H}$

$$
\mathrm{W}=\left(166,266 \text { pixels }^{2} / 600 \text { pixels }\right)=277.11 \text { pixels }
$$

- The image was analyzed at 72 pixels/inch, thus

$$
\begin{aligned}
& W=(277.11 \text { pixels }) /(72 \text { pixels } / \text { inch })=3.85 \text { in } \\
& W=(3.85 \text { in. }) *(2.540 \mathrm{~cm} / \text { in. })=9.78 \mathrm{~cm}
\end{aligned}
$$

- Image is magnified 2050 times, thus

$$
\begin{aligned}
& \mathrm{W}=(9.78 \mathrm{~cm}) /(2050 \mathrm{X})=4.77 \times 10^{-3} \mathrm{~cm} \\
& \text { or } \\
& \underline{W}=0.0047 \mathrm{~cm}
\end{aligned}
$$




\subsection{References}

1. P. J. Rodriguez, K. Axler, P. Lopez, and R. Pereyra, "Ultra-Corrosive Resistant Composite Materials for Various Chemical Processing Applications: CarbonSaturated Tantalum," TMS Annual International Conference (February 1996).

2. L. L. Shreir, "Corrosion: Metal/Environment Reactions," Vol. 1, NewnesButterworths, Boston, Mass., pp. 5:59 (1977).

3. K. M. Axler, "Engineered Materials for Application in Severe Metallurgical Environments: Tantalum-Carbon Alloy Development," Ph.D. Dissertation, Colorado School of Mines and Los Alamos National Laboratory Report LA-12876-T, (February 1995).

4. A.E. Van Arkel, "The Structure of Mixed Crystals," Physica 4, pp. 33-41 (1924).

5. K. Becker and F. Ebert, "The Crystal Structure of Some Binary Carbides and Nitrides," Z. Physik 31, pp. 268-275 (1925).

6. M. Schwarz and O. Summa, "The Crystal Structure of Tantalum Carbide," Metallwirtschaft 12, p. 298 (1933).

7. L.P. Molkov and A.V. Chochlova, "Tantalum Carbide Hard Alloys," Redkie Metal. 1, pp. 24-30 (1935).

8. P.M. McKenna, "Tantalum Carbide: Its Relation to Other Hard Refractory Compounds," Ind. Eng. Chem. 28, pp. 767-771 (1936).

9. A.E. Kovalsky and J.S. Umanski, "The Interactions of the Monocarbides of Tungsten, Tantalum, and Niobium," Zhur. Fiz. Khim. 20, pp. 773-778 (1946).

10. H. Krainer and K. Konopicky, "Investigation of Sintered Hard Metals," Berg. Hutternmann Monatsh. 92, pp. 166-178 (1947).

11. H. Nowothy and R. Kieffer, "X-ray Investigation of Carbide Systems," Z. Metallkunde 2, pp. 257-265 (1947). 
12. J.T. Norton and A.L. Mowry, "Solubility relationships of the Refractory

Monocarbides," J. Metals 1, No. 2 Trans., pp. 133-136 (1949).

13. W.G. Burgers and J.C.M. Basart, "Formation of High-Melting Metallic Carbides by Igniting a Carbon Filament in the Vapor of Volatile Halogen Compound of the Metal," Z. Anorg. Chem. 216, pp. 209-222 (1934).

14. F.H. Ellinger, "The Tantalum-Carbon System," Trans ASM 31, pp. 89-104 (March 1943).

15. Constitution of Binary Alloys, M. Hansen, Ed. (Genium Publishing, Schenectady, New York, 1991).

16. Constitution of Binary Alloys, Second Supplement, F.A Shunk, Ed. (Genium Publishing, Schenectady, New York, 1991).

17. R. Keiffer and F. Benesovsky, Hartstoffe, (Springer Publishing, Vienna, Austria 1963).

18. E. Rudy and D. P. Harmon, "Ternary Phase Equalibria In Transition Metal-BoronCarbon-Silicon Systems, Part I. Related Binary Systems, Volume V. Ta-C System," Air Force Materials Laboratory Report AFML-TR-65-2, Part I, vol. 5, Wright-Patterson AFB (December 1965).

19. E. K. Storms and N. H. Krikorian, "The Variation of Lattice Parameters with Carbon Contents of Niobium Carbide," J. Phys. Chem 63, pp. 1747-1749 (1960).

20. The Handbook of Binary Phase Diagrams, W.G. Moffat, Ed., (Genium Publishing, Schenectady, New York, January 1984).

21. E. Rudy and D. P. Harmon, "Compendium of Phase Diagram Data," Air Force Materials Laboratory Report AFML-TR-65-2, Wright-Patterson AFB, (June 1969).

22. M. G. Bowman, "The High Temperature Chemistry of Refractory Carbides as Determined by High Temperature Techniques," in Plansee Proceedings, 5th Plansee Seminar, "Metals for the Space Age," (Reutte, Tirol, Austria) pp. 701-711 (1964). 
23. C. F. Zalabak, "The Melting Points of Tantalum Carbide and Tungsten," NASA Report, NASA-TN-D-761 (1961).

24. M. R. Nadler and G. P. Kempter, "Thermal Decomposition of Niobium and Tantalum Monocarbides," J. Phys. Chem. 32, pp. 1477-1481 (1960).

25. L. D. Brownlee, "The Pseudo-Binary Systems of Uranium Carbide with Zirconium Carbide, Tantalum Carbide, and Niobium Carbide," J. Inst. Met. 87, pp. 56-81 (1958).

26. G. A. Geach and F. O. Jones, "Interactions in Mixtures of Hard Materials at Very High Temperatures," Met. Abstr. 24, p. 366 (1957).

27. C. Agte and H. Alterthum, "Systems of High-Melting Carbides; Contributions to the Problem of Carbon Fusion," Z. Techn. Physik 11, pp. 182-191 (1930).

28. E. Friederich and L. Sittig, "The Preparation and Properties of Carbides," Z. Anorg. Chem. 144, pp. 169-189 (1925).

29. N. H. Krikorian, T. C. Wallace, R. Krohn, and M. G. Bowman "The Formation of Carbide Surfaces on Tantalum and Tantalum-Tungsten Alloys," in "Proceedings of the 3rd International Symposium on High-Temperature Technology," Pacific Grove, California, pp. 421-432 (1967).

30. W. F. Brizes, "Diffusion of Carbon in the Carbides of Tantalum," J. of Nuclear Materials 26, pp. 227-231, (1968).

31. R. Resnick, R. Steinitz, and L. Seigle, "Determination of Diffusivity of Carbon in Tantalum and Columbium Carbides By Layer-Growth Measurements," Trans. Met. Soc. AIME, vol. 233, pp. 1915-1918, Oct. (1965)

32. E. Fromm, E. Gebhardt, and U. Roy, "Diffusion of Carbon in the Carbides of Tantalum," Z.Metallk, vol. 57, pp. 808, (1966)

33. M. W. Weiser, "Advanced Material Science for Engineers," 4th Draft Edition, pp 246, (1994) 
34. R. Resnick and L. Seigle, "The Diffusion of Carbon in Tantalum Monocarbide," Trans. Met. Soc. AIME, vol. 236, pp. 1732-1738, Dec. (1966).

35. J. M. Tobin, L. M. Adelsberg, L. H. Cadoff, and W. F. Brizes, "Carbon Diffusion in the Group IVB and VB Transition Element Monocarbides," Prodeedings of the Conference on Nuclear Applications of Non-Fissionable Ceramics, American Ceramics Society, pp. 257277, (1967).

36. R. W. Powers and M. V. Doyle, "Diffusion of Intersititial Solutes in the Group V Transition Metal," J. Applied Physics, 30, vol. 4, pp. 514-524, April, (1959).

37. J. L. Snoek, "Theory of the Elastic After Effect and the Diffusion of Carbon in Alpha-Iron," Phillips Research Report, vol. 1, pp. 5, (1945).

38. V. I. Smirnova and B. F. Ormont, "Relation of Heats and Free Energies of Formation of Tantalum Carbides to Phase and Chemical Composition," Doklady Akad. Nauk USSR, vol. 100, No. 1, (1955).

39. M. K. Pochon et al., "Reaction Metals," W. R. Clough (ed.), Interscience, NY, (1959).

40. D. A. Vaughan, O. M. Stewart, and C. M. Schwartz, "Determination of Interstitial SolidSolubility Limit in Tantalum and Identification of the Precipitate Phase," U. S. Atomic Energy Commission Report, BMI-1472, pp. 70, (1960).

41. H. R. Ogden, F. F. Schmidt, and E. S. Bartlett, "The Solubility of Carbon in Tantalum," Trans. Met. Soc. of AIME, vol. 227, pp. 1458-1460, Dec. (1963).

42. E. K. Storms, “A Critical Review of Refractory Materials,” Los Alamos National Laboratory Report LA-MA-2674, pp. 54-65, March, (1962)

43. E. Fromm and U. Roy, "The High-Temperature Solid Solubility Limit of Carbon in Tantalum," J. Less Common Metals, vol. 8, pp. 73-75, (1965).

44. G. Hortz, K. Lindenmaier, and R. Klaiss, "High-Temperature Solid Solubility Limit of Carbon in Niobium and Tantalum," J. Less Common Metals, vol 35, pp. 97-105, (1974). 
45. J. Crank, The Mathematics of Diffusion," 2nd Ed., Oxford Science Publication (1975).

46. R. L. Andelin, L. D. Kirkbride, and R. H. Perkins, "High-Temperature Environmental Testing of Liquid Plutonium Fuels," Los Alamos Scientific Laboratory Report LA-3631 (July 1967).

47. J. A. Leary and L. J. Mullins, "Preparation of Ultra-High Purity Plutonium," Los Alamos Scientific Laboratory Report LA-3356-MS (July 1965).

48. K. M. Axler, P.C. Lopez, G. L. DePoorter, and R. Pereyra, "Process and Charaterization of Engineered Materials in the Tantalum-Carbon System," Proceedings First International Conference on Processing Materials for Properties, Hawaii, pp. 221 (November 1993).

49. P. Lopez, "Saturation Process of Tantalum Hardware and Crucibles," Los Alamos National Laboratory, Nuclear Materials Technology Division Internal Report NMT-3:94008 (January 1995).

50. R. Pereyra, "Stain Etching of TaW/TaC," Los Alamos National Laboratory, Nuclear Materials Technology Division Internal Report NMT-1-94-005 (July 1993).

51. T. C. Wallace and D. P Butt, "Diffusion and Vaporization of Transition Metal Carbides as it Relates to Diffusion coupled Carburization Process: A Review," Los Alamos National Laboratory Report LA-UR-93-2903 (1993). 


\section{'}

